Purdue University

Purdue e-Pubs

2017

\title{
Quantitative Evaluation of the Dependence of Pool Boiling Heat Transfer Enhancement on Sintered Particle Coating Characteristics
}

S. Sarangi

JA. Weibel

Purdue University, jaweibel@purdue.edu

S V. Garimella

Purdue University, sureshg@purdue.edu

Follow this and additional works at: http://docs.lib.purdue.edu/coolingpubs

Sarangi, S.; Weibel, J A.; and Garimella, S V., "Quantitative Evaluation of the Dependence of Pool Boiling Heat Transfer Enhancement on Sintered Particle Coating Characteristics" (2017). CTRC Research Publications. Paper 309.

http://dx.doi.org/10.1115/1.4034901

This document has been made available through Purdue e-Pubs, a service of the Purdue University Libraries. Please contact epubs@purdue.edu for additional information. 


\author{
Suchismita Sarangi \\ School of Mechanical Engineering; \\ Birck Nanotechnology Center, \\ Purdue University, \\ 585 Purdue Mall, \\ West Lafayette, IN 47907 \\ Justin A. Weibel \\ School of Mechanical Engineering; \\ Birck Nanotechnology Center, \\ Purdue University, \\ 585 Purdue Mall, \\ West Lafayette, IN 47907

\section{Suresh V. Garimella ${ }^{1}$ \\ School of Mechanical Engineering; Birck Nanotechnology Center, Purdue University, 585 Purdue Mall, West Lafayette, IN 47907}

Quantitative Evaluation of the Dependence of Pool Boiling Heat Transfer Enhancement on Sintered Particle Coating Characteristics

\begin{abstract}
Immersion cooling strategies often employ surface enhancements to improve the pool boiling heat transfer performance. Sintered particlelpowder coatings have been commonly used on smooth surfaces to reduce the wall superheat and increase the critical heat flux $(\mathrm{CHF})$. However, there is no unified understanding of the role of coating characteristics on pool boiling heat transfer enhancement. The morphology and size of the particles affect the pore geometry, permeability, thermal conductivity, and other characteristics of the sintered coating. In turn, these characteristics impact the heat transfer coefficient and CHF during boiling. In this study, pool boiling of FC-72 is experimentally investigated using copper surfaces coated with a layer of sintered copper particles of irregular and spherical morphologies for a range of porosities ( 40-80\%). Particles of the same effective diameter $(90-106 \mu \mathrm{m})$ are sintered to yield identical coating thicknesses ( 4 particle diameters). The porous structure formed by sintering is characterized using microcomputed tomography $(\mu-C T)$ scanning to study the geometric and effective thermophysical properties of the coatings. The boiling performance of the porous coatings is analyzed. Coating characteristics that influence the boiling heat transfer coefficient and CHF are identified and their relative strength of dependence analyzed using regression analysis. Irregular particles yield higher heat transfer coefficients compared to spherical particles at similar porosity. The coating porosity, pore diameter, unit necking area, unit interfacial area, effective thermal conductivity, and effective permeability are observed to be the most critical coating properties affecting the boiling heat transfer coefficient and CHF. [DOI: 10.1115/1.4034901]
\end{abstract}

\section{Introduction}

The semiconductor industry has witnessed a continuous miniaturization of modern electronic circuits with increasing power consumption per unit footprint area. To keep up with these power density trends, advances in electronics thermal management are essential. Immersion cooling by pool boiling from heated surfaces offers one of the more efficient methods for high-heat-flux dissipation, due to its passive nature and the high heat transfer coefficients obtained. Many variants of surface modifications have been developed and studied to further enhance pool boiling performance.

A common modification for enhancing pool boiling heat transfer is to sinter thermally conductive particles onto a surface to form a porous structure, as investigated early on by Milton [1]. A number of studies have since explored various processing methods and geometric modifications for this structure, such as modulated porous copper coatings with periodic variations in layer thickness [2], a silver flake-based boiling enhancement paint [3], spray-coated alumina particulate layers [4], and porous graphite layers with randomly interconnected microscale pores $[5,6]$, and observed significant enhancement of the heat transfer coefficient and critical heat flux (CHF).

While different geometric surface modifications have been postulated for boiling enhancement, few have expressly analyzed the parametric effects of individual sintered coating characteristics (e.g., particle size, porosity, and thickness), by varying one

\footnotetext{
${ }^{1}$ Corresponding author.

Contributed by the Heat Transfer Division of ASME for publication in the JourNAL OF HEAT TRANSFER. Manuscript received April 12, 2016; final manuscript received September 16, 2016; published online November 8, 2016. Assoc. Editor: Debjyoti Banerjee.
}

parameter at a time while keeping all others fixed. Nishikawa et al. [7] studied the enhancement of refrigerant boiling from different sizes and thicknesses of copper and bronze sintered powders on copper tubes. The maximum heat transfer coefficient was obtained when the coating thickness was about four times the mean particle diameter $(\delta / d=4)$, with copper powder being more effective than bronze. A model formulated by Ranjan et al. [8], which considered the porous structure as being analogous to extended fins, showed that the optimum wick thickness occurred when the effective area enhancement was maximized. Sarangi et al. [9] studied the effect of particle size variation on copper surfaces coated with sintered spherical copper particles, for particle sizes varying from 45 to $1000 \mu \mathrm{m}$. The sintered coatings were manufactured with a constant thickness-to-diameter ratio $(\delta / d=4)$ and porosity of $30-40 \%$. It was observed that a particle size range of 90-106 $\mu \mathrm{m}$ provided the highest heat transfer coefficient, while 45-53 $\mu$ m-diameter particles provided the maximum CHF for pool boiling of FC-72. Furberg and Palm [10] studied the boiling heat transfer characteristics from a dendritic microporous copper surface in R134a and FC-72. The bubble departure size and frequency were visualized, and the heat transfer coefficient (along with delineation of the latent and sensible heat contributions) was measured over a range of heat fluxes. The latent heat contribution, estimated from visualization of the bubble departure frequency and diameter, was enhanced by up to ten times for the microporous surface as compared to a smooth surface. The dendritic porous structure was also said to increase agitation of the vapor bubbles inside the porous structure, thus enhancing single-phase convection heat transfer by up to six times. O'Hanley et al. [11] performed experiments to study the effect of porosity on CHF during boiling of water from surfaces with different geometric 
properties (e.g., surface wettability and roughness). Silica nanoparticles were deposited on sapphire substrates to achieve the desired coating properties. Porous surfaces showed up to a $60 \%$ higher $\mathrm{CHF}$ than nonporous surfaces for hydrophilic surfaces. It was concluded that for surfaces having similar wettability characteristics, porosity plays a major role in determining the $\mathrm{CHF}$ behavior during boiling. Li and Peterson [12] performed experiments to study the effects of coating thickness, porosity, and mesh size on the CHF during pool boiling of water from surfaces coated with sintered copper screen mesh. For coatings with the same thickness and mesh sizes, there was an optimal porosity at which the CHF reached a maximum value due to a trade-off between capillary pressure within the pores and hydraulic flow resistance.

Since the morphology of the individual particles affects the postsintering pore shape, permeability, surface roughness, and effective conductivity and diffusivity of the coating, it can be expected to significantly influence the heat transfer coefficient and CHF during boiling. Prior studies on pool boiling have not explicitly investigated the effect of particle morphology; however, several studies have explored the effects of particle morphology on effective geometric and thermophysical properties for other heat transfer applications. Chi et al. [13] studied the effects of shape variations on the thermal properties of coatings. Various particle shapes such as angular/polyhedral, globular/rough-textured, and hollow spheres were studied for powder-based yttria-stabilized zirconia (YSZ), molybdenum, and silicon thermal-spray coatings. Different initial particle shapes and sintering conditions were used for fabrication of the coating, resulting in different pore structure and porosities. The resulting thermal conductivity and diffusivity were shown to be more dependent on pore architecture than on the porosity of the coatings. The thermal conductivity of globular/ irregular particle coating was found to be almost twice that of the hollow spherical powder coating. Dixon [14] studied the effect of particle morphology on the convective heat transfer at varying flow rates through packed beds with spherical, cylindrical, and hollow cylindrical particles. The different particle shapes had a significant effect on the effective conductivity and wall heat transfer coefficient of the packed beds. Cylindrical particle beds showed higher thermal conductivity and heat transfer coefficient compared to spherical particle beds, while minimal difference was observed between the full and hollow cylinders. The effect of particle shape and size on flow boiling performance of porous copper microchannel heat sinks constructed from spherical and irregularshaped particles (50-150 $\mu \mathrm{m}$ effective diameter) was investigated by Deng et al. [15]. Irregular-shaped particles of the smallest size $(50-75 \mu \mathrm{m})$ showed the highest heat transfer coefficient, while spherical particles of the smallest particle size showed the lowest heat transfer coefficient. Lin and Hwang [16] conducted experiments to study the effect of particle morphology and sintering conditions on the permeability of sintered powders for heat pipe applications. Three different particle shapes (irregular, dendritic, and spherical) were evaluated with varying compacting pressure and temperature during sintering. It was observed that gasatomized spherical particles had the lowest porosity but the highest permeability. Permeability may be estimated by the Kozeny-Carman equation [17]

$$
K=\frac{d^{3} \varepsilon^{3}}{C(1-\varepsilon)^{2}}
$$

where $C$ is a geometric factor depending on the particle morphology and manufacturing process. While Eq. (1) dictates that a higher coating porosity would result in a higher permeability, the morphology-dependent factor $C$ can significantly alter the permeability.

To determine the properties of porous media, several studies [18,19] have used unit-cell models or simplified analytical/semi-empirical models to evaluate the pore-scale transport characteristics, which can then be used to solve macroscale governing equations using effective properties. A review of these methods and their applications is provided in Ref. [20]. The accuracy of such modeling is limited for porous media with a high degree of randomness and irregularities, such as sintered particle coatings. An alternative modeling approach involves direct simulation of transport within the actual porous microstructure geometry obtained using imaging techniques such as microcomputed tomography $(\mu-\mathrm{CT})[21,22]$. Tabor et al. [23] demonstrated a voxel-based three-dimensional (3D) reconstruction method for generating finite-volume meshes from $\mu$-CT data to represent the complex structure of porous media. Bodla et al. used $\mu$-CT scanning to simulate the thermal conductivity, permeability, and convective heat transport characteristics of open-celled aluminum foams [24] and sintered copper particle coatings [25]. A strong dependence of the coating characteristics on the sintering conditions was demonstrated.

The present study aims to investigate the effects of geometric properties (viz., particle morphology, porosity, pore size, postsintering particle size, particle sphericity, and interfacial and necking areas per unit volume) and effective thermophysical properties including permeability and thermal conductivity on the pool boiling performance of sintered particle coatings over a wide range of porosities. The surfaces are designed and fabricated to keep presintering particle size, particle material, and coating thickness constant while varying particle morphology and coating porosity to evaluate these effects. A detailed $\mu$-CT characterization of the coating is performed to obtain the geometric properties; numerical simulations are performed on the reconstructed porous domains to obtain the effective thermophysical properties. A regression analysis is used to quantitatively evaluate sensitivities of the pool boiling heat transfer coefficient and $\mathrm{CHF}$ to these coating characteristics.

\section{Experimental Methods}

2.1 Pool Boiling Test Facility. Figure 1 shows a schematic diagram of the pool boiling test facility. An abbreviated description is provided here for this modified version of the facility used by Sarangi et al. [9]. The base heater assembly consists of a copper heater block embedded in an insulation casing. The copper block has a $25.4 \mathrm{~mm} \times 25.4 \mathrm{~mm}$ top surface coated with sintered particles. The heater width is sufficiently large such that it should not influence CHF [26]. The heat input is provided by 12 cartridge heaters $(100 \mathrm{~W}$ each) inserted into holes in the bottom surface of the block. Block temperatures are measured using T-type thermocouples inserted into tapped holes along three rakes, as shown in Fig. 1. The copper block is inserted into a block of PEEK, a machinable, low thermal conductivity $(0.28 \mathrm{~W} / \mathrm{m} \mathrm{K})$ thermoplastic that

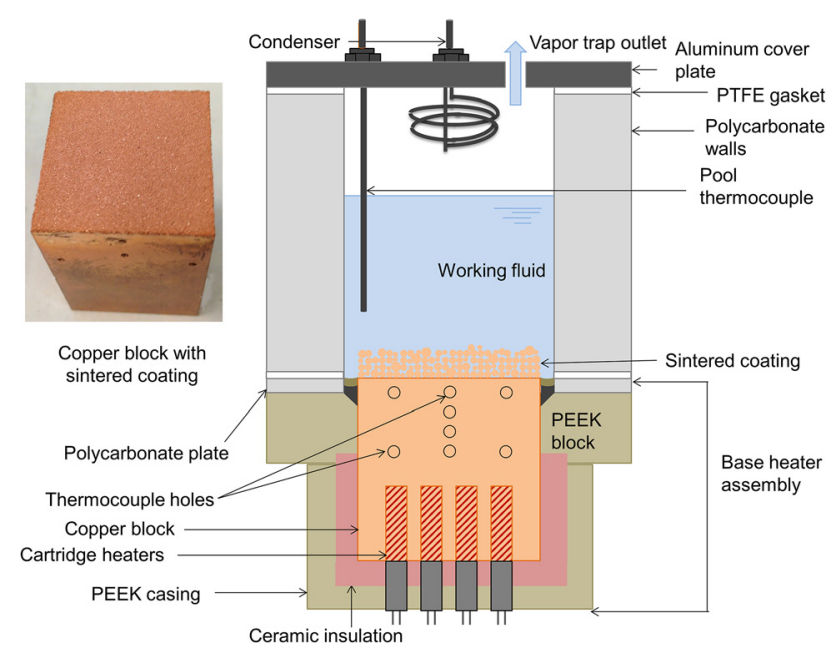

Fig. 1 Schematic diagram of test facility with inset showing a photograph of a copper block coated with spherical sintered particles 
(a)
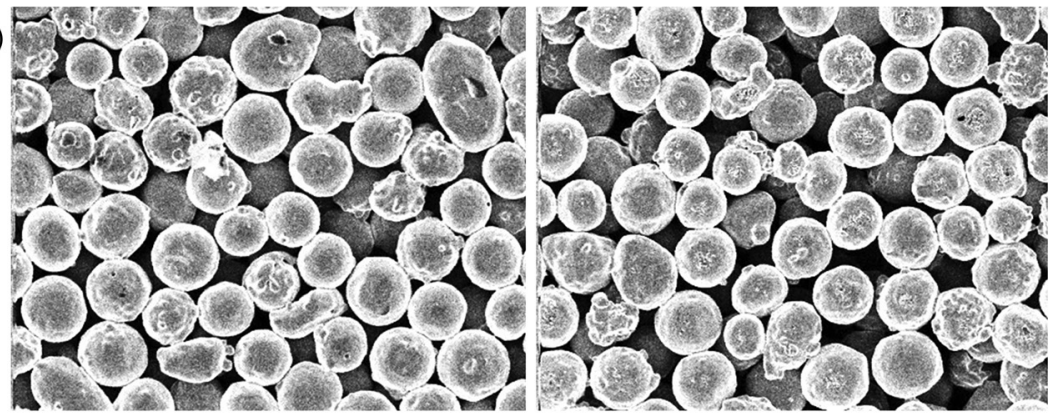

Porosity $=39 \%$

Porosity $=55 \%$

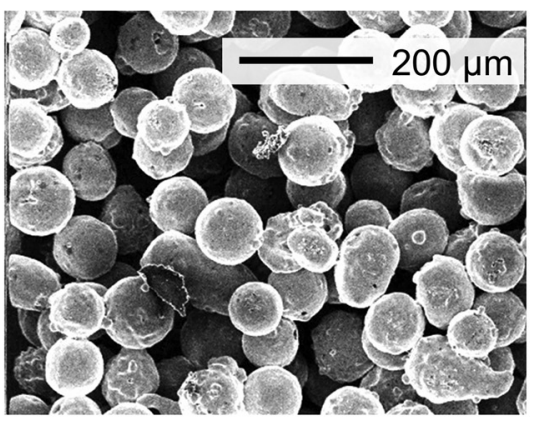

Porosity $=79 \%$
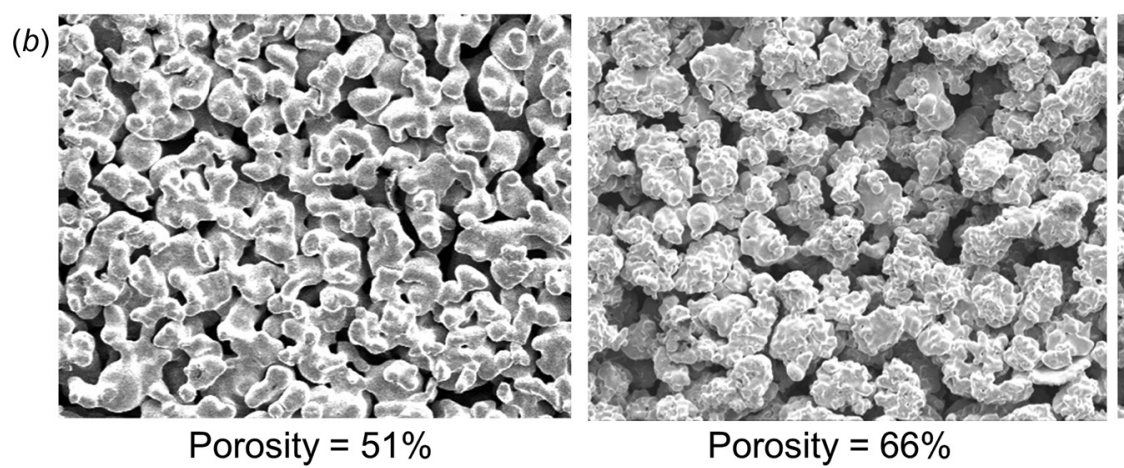

Porosity $=66 \%$

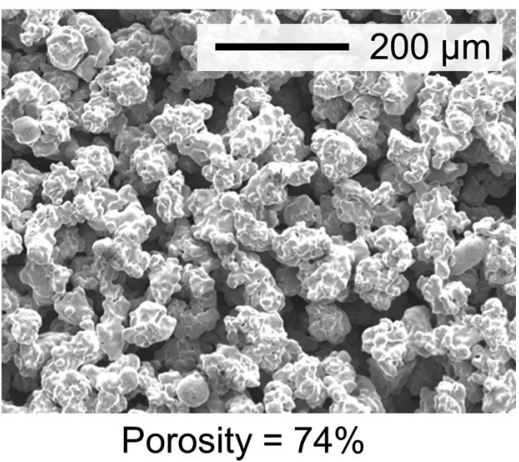

Fig. 2 SEM images of (a) spherical and (b) irregular coatings at a low, intermediate, and high porosity, showing the pore structure of the coatings

can withstand temperatures up to $250^{\circ} \mathrm{C}$. A $0.8 \mathrm{~mm}$-thick polycarbonate plate is attached to the top of the PEEK block; the copper block is aligned such that it protrudes just above the polycarbonate plate as shown. The vertical location of the thermocouple rake and the thickness of polycarbonate plate have been slightly altered from the original design [9]. The lower part of the copper block is insulated as described in Ref. [9].

The pool boiling chamber comprises four polycarbonate walls sealed together with RTV silicone that is cured under compression with screws. The chamber is sealed to the base heater assembly with a compressed PTFE gasket. An aluminum cover plate seals the top of the chamber walls by compressing another PTFE gasket, forming a $30.48 \mathrm{~mm} \times 30.48 \mathrm{~mm} \times 93.9 \mathrm{~mm}$ sealed chamber enclosing the working fluid on the heated surface. A T-type thermocouple routed through the cover plate is used to measure the pool temperature during testing. A chilled 50-50\% water-glycol mixture is cycled through the condenser at a flow rate of $0.51 / \mathrm{min}$ at $15{ }^{\circ} \mathrm{C}$ using a chiller (ULT-80, Neslab) to condense vapor during testing. A $6.35 \mathrm{~mm}$-diameter polyurethane tube connects the liquid pool to a vapor trap that is open to the ambient during testing and maintains the pool at atmospheric pressure. The chiller flow rate and set-point temperature were selected to ensure that no working fluid collects in the vapor trap during the experiment (to prevent fluid loss from the chamber over time).

2.2 Fabrication of Test Surfaces. Copper particles having two different morphologies_-irregular and spherical-were used to fabricate the test surfaces. The differences in morphology are brought about by the particle fabrication method. As described in Refs. [27,28], irregular particles are produced by water atomization and spherical particles by air atomization. Irregular particles appear as roughened spheroidal shapes, while spherical particles are smooth. Figure 2 shows representative images of the particle shapes observed using a scanning electron microscope (SEM). The SEM images are taken after testing. Due to the different morphology of the particles, the native packing porosity before sintering is different (48\% for spherical particles and $60 \%$ for irregular particles). The sintered-coating fabrication method is adjusted to achieve a range of porosities for each particle shape. This requires either reducing or increasing the native packing density of the powder. The porosity of the coating can be reduced by controlling the sintering time and temperature to achieve the desired porosity [9]. In order to increase the porosity beyond the native packing density, the most commonly used method is lostcarbonate sintering (LCS) [29]. A mixture of spherical metal particles, carbonate, and a binder is sintered at high temperature under pressure until the carbonate decomposes or melts, leaving behind a porous metal coating. The carbonate particle size and percentage, as well as the sintering temperature and time, can be controlled to produce porous coatings with the desired porosity and pore diameter.

The top surface of the copper heater block is prepared for sintering by sanding with progressively finer diamond sanding sheets $(9 \mu \mathrm{m}, 3 \mu \mathrm{m}$, and $0.1 \mu \mathrm{m})$ followed by metal polishing (Simichrome, Happich, Wuppertal, Germany). The irregular particles (ACuPowder International) and the spherical particles (Alfa Aesar) are first sieved into the desired size range of 90-106 $\mu \mathrm{m}$. The range is selected based on the particle size that yielded the best pool boiling heat transfer performance for spherical sintered coatings at $\sim 40 \%$ porosity in a prior study [9]. The particles are cleaned by soaking in acetone and rinsing with methanol. To sinter the porous layers with a reduced porosity, loose copper powder is first poured into a graphite mold and leveled off to the desired height. The initial layer thickness of particles is varied, as required, to obtain a final layer thickness-to-particle diameter ratio, $\delta / d$, of $\sim 4$, which has been shown to have the maximum heat transfer coefficient in previous studies [7,30]. The copper block is then gently placed face-down on top of the powder and the assembly is placed in an evacuated furnace. The temperature is steadily ramped up to $950{ }^{\circ} \mathrm{C}$ and held at this temperature under vacuum for the desired time as shown in Table 1. The assembly is then allowed to gradually cool to room temperature under vacuum and inspected under an optical microscope at multiple locations to ensure a uniform coating thickness. 
Table 1 Sintering conditions and resulting porosity of the spherical and irregular sintered particle coatings fabricated

\begin{tabular}{lccc}
\hline \hline Particle shape & Carbonate weight fraction $(\%)$ & $\delta / d$ & $\varepsilon(\%)$ \\
\hline \multirow{2}{*}{ Spherical } & 0 & 3.9 & 39 \\
& 0 & 3.9 & 45 \\
& 10 & 4.4 & 55 \\
& 45 & 4.1 & 68 \\
& 60 & 3.7 & 72 \\
& 80 & 4.2 & 79 \\
Irregular & 0 & 3.8 & 51 \\
& 10 & 4.2 & 58 \\
& 45 & 3.5 & 66 \\
& 60 & 3.5 & 71 \\
& 80 & 3.9 & 74 \\
\hline \hline
\end{tabular}

For the cases where the porosity needs to be increased, an LCS method is used. The copper particles are mixed with spherical potassium carbonate particles $(90-150 \mu \mathrm{m})$, with a weight fraction as shown in Table 1 to achieve the desired porosity. A small amount of ethanol is added to act as a binder in the mold, and the particles are mechanically stirred to ensure uniform mixing. This mixture is then poured into the mold to the desired height and placed in the evacuated furnace. The temperature of the furnace is steadily ramped up to $850^{\circ} \mathrm{C}$ and then held for $\sim 2 \mathrm{~h}$ to initiate the sintering process. The temperature is then ramped up further to $950^{\circ} \mathrm{C}$ for $\sim 30 \mathrm{~min}$ to decompose the carbonate particles (melting point of $891^{\circ} \mathrm{C}$ ), leaving behind open pores. The assembly is then allowed to cool gradually. This sintering recipe was selected because it has been shown to produce a clean and well-bonded porous structure for the desired porosity range, and does not require any postprocessing to remove the potassium carbonate from the sintered matrix [29].

Table 1 shows the coating porosity and thickness after the sintering procedure for all the samples fabricated. The weight of the copper block is measured before and after the sintering process. The height of the coating is measured from images observed under SEM. From these measures, the porosity of the coating can be obtained by comparing the density to that of solid copper. Based on propagation of the initial measurement uncertainties, the uncertainty in measured porosity values is calculated to be $2-4 \%$ for the different cases. Figure 2 shows representative images of the pore structures observed using a scanning electron microscope (SEM).

2.3 Experimental Procedure. To conduct an experiment, the sintered copper block is first assembled into the test facility. The $0.8 \mathrm{~mm}$-thick polycarbonate plate is mounted on the PEEK block to surround the test surface. A chamfer in the PEEK block creates a groove around the outer edges of the test block, which assists in sealing at this location. A layer of RTV silicone sealant is first filled in the groove and cured in an oven for $90 \mathrm{~min}$ at $75^{\circ} \mathrm{C}$, followed by the application of a topping layer of epoxy (E 5302 High Temp Epoxylite). The silicone prevents the wicking of epoxy into the gap between the test piece and insulation, thereby facilitating easier removal of test pieces between tests; the highviscosity paste epoxy, on the other hand, seals out the working fluid, without itself seeping into the pores of the sintered surfaces. The test chamber walls are then secured onto the base and the assembly is cured in the oven for $\sim 20 \mathrm{~h}$ at $80^{\circ} \mathrm{C}$.

The assembled test chamber is mounted onto a support stand and filled with $40 \mathrm{ml}$ of FC-72 $\left(T_{\text {sat }}=56^{\circ} \mathrm{C}, \rho=1594 \mathrm{~kg} / \mathrm{m}^{3}\right.$, $\mu=4.3 \times 10^{-4} \mathrm{~kg} / \mathrm{m} \quad \mathrm{s}, \quad k=0.054 \mathrm{~W} / \mathrm{m} \quad \mathrm{K}, \quad h_{f g}=88 \mathrm{~kJ} / \mathrm{kg}$, $c_{p}=1101 \mathrm{~J} / \mathrm{kg} \mathrm{K}$, and $\gamma=0.010 \mathrm{~N} / \mathrm{m} \mathrm{[31]).} \mathrm{The} \mathrm{cover} \mathrm{plate} \mathrm{is} \mathrm{then}$ secured. The fluid is first degassed by boiling aggressively for $2 \mathrm{~h}$. After degassing, the heat flux is increased in predetermined steps using the cartridge heaters embedded in the copper block to obtain a boiling curve. Steady-state conditions are assumed to have been reached when the change in calculated surface temperature versus time at each heat flux setting is less than $0.02^{\circ} \mathrm{C} / \mathrm{s}$ over $30 \mathrm{~min}$. Once this steady-state criterion is satisfied, the temperature data collected over $120 \mathrm{~s}$ are time-averaged for subsequent postprocessing of the surface heat flux and temperature. The procedure is continued until $\mathrm{CHF}$ is reached, which is marked by a sudden rapid rise in temperature, following which, the power to the heaters is shut off and the system is allowed to cool down. The porous coating was confirmed to maintain a highly wetting contact to the fluid after fabrication and testing; multiple boiling curves were obtained to confirm the negligible effect of surface degradation between consecutive tests. Tests were also conducted with the heat flux being decreased in steps from the maximum value to evaluate if significant hysteresis is observed in the system. As described in Sarangi et al. [9], area-averaged wall temperature and heat flux are calculated from the temperature gradients along the three thermocouple rakes. The extrapolated wall temperature is first calculated from each of these rakes by linear regression. The area-averaged wall temperature is then calculated using a weighting of each local temperature based on the surface areas corresponding to each rake. Note that this heat flux is based on the sample footprint area, not the surface area of the porous coating. Following the uncertainty analysis procedure described in Ref. [9], for a calibrated absolute thermocouple temperature measurement uncertainty of $\pm 0.23^{\circ} \mathrm{C}$, the area-averaged heat flux uncertainty is $\pm 4-5.5 \mathrm{~kW} / \mathrm{m}^{2}$ over the range of heat fluxes investigated $\left(\sim 4-250 \mathrm{~kW} / \mathrm{m}^{2}\right)$.

\section{Coating Characterization}

3.1 Sample Preparation and Imaging. For sintered particle coatings such as those used in the present work, the high degree of randomness and irregularity makes it difficult to use simplified analytical or representative unit-cell models to accurately predict the coating properties. In the present work, microcomputed tomography $(\mu-\mathrm{CT})$ is used to resolve the exact 3D structure of the porous coatings for subsequent characterization.

After the pool boiling test is completed, samples are carefully excised from the copper block surface over a $5 \mathrm{~mm} \times 5 \mathrm{~mm}$ footprint area, preserving the original thickness of the coating. The samples are lightly pressed between two smooth surfaces to flatten out any warping of the samples. The prepared samples are then imaged (Skyscan 1172) at a resolution of $4 \mu \mathrm{m}$ using a $100 \mathrm{kV} \mathrm{X}$ ray source voltage. The scans were performed in the Department of Anatomy and Cell Biology, Indiana University School of Medicine, Indianapolis, IN. The scanner software generates a twodimensional (2D) stack of images corresponding to the 3D object.

3.2 Image Processing. The stack of $2 \mathrm{D}$ images generated from the $\mu$-CT scans is imported into the commercial software package SIMPLEWARE [32] for image processing (ScanIP module) and mesh generation (+FE module). The details of the image processing steps are briefly described here and a more detailed description may be found in Ref. [25]. Example images at each processing step are shown in Fig. 3 for a reduced portion of the domain. The image processing steps in Fig. 3 are shown for a single 2D slice for clarity, but all the steps are performed on a 3D volume. Each 2D image of unit-pixel thickness from the stack is "stitched" with adjacent image slices to generate a 3D volume as shown in Fig. 3(b). Copper has much higher X-ray absorptivity than air that fills the surrounding pore region during scanning; hence, the brighter regions correspond to copper and darker regions correspond to the pore space in the image. The transition between these regions is not discrete in the images. In order to accurately differentiate the two regions, a grayscale threshold value is selected such that the porosity of the reconstructed $3 \mathrm{D}$ volume matches the measured porosity of the sample. Figure 3(c) shows an image slice after thresholding. The domains are then inspected for unphysical unconnected regions or islands, which 


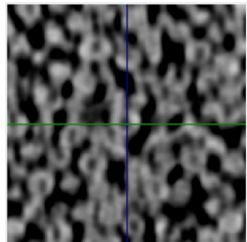

(a)

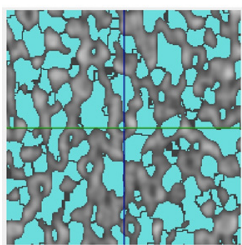

(c)

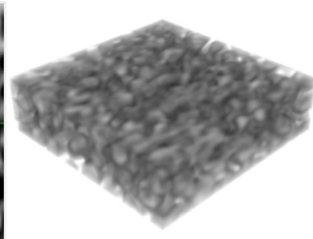

(b)

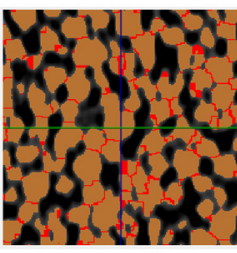

(d)

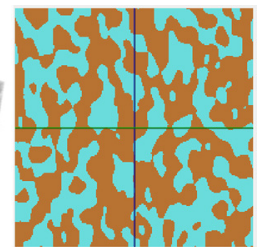

(c)

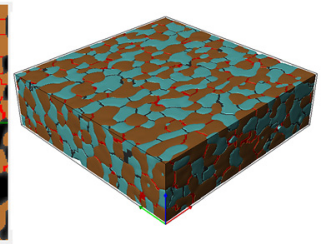

$(e)$
Fig. 3 Image processing steps showing (a) raw 2D slice from $\mu$-CT scan, (b) 3D reconstructed volume, (c) 2D slice showing pore domain (lighter region) and copper regions after thresholding, (d) segmented pore domain, (e) segmented copper domain, and $(f) 3 \mathrm{D}$ reconstructed volume segmentation in both pore and copper domains. An overall domain size of $800 \mu \mathrm{m} \times 800 \mu \mathrm{m} \times 207 \mu \mathrm{m}$ for the spherical particle coating at $39 \%$ porosity is shown.

are removed (typically less than four particles or pores over the entire volume scanned). Figure 4 shows the 3D solid volumes generated for several of the spherical and irregular particle coatings over the range of porosities investigated.

3.3 Evaluation of Geometric Coating Properties. The microscale particles fuse together during the process of sintering, forming one connected 3D volume. It is necessary to identify individual particles and pores to characterize the geometric properties of the coating. This is achieved by using the watershed algorithm available in the SIMPLEWARE ScanIP module [32]. After segmentation of the individual particles and pores, as shown in Figs $3(d)-3(f)$, the statistical distribution of particle diameter $\left(d_{\text {part }}\right)$ and pore diameter $\left(d_{\text {pore }}\right)$ is obtained for each coating, based on the equivalent spherical volume of each segmented particle/pore. The sphericity $(\phi)$ is defined as

$$
\phi=\frac{\pi^{1 / 3}(6 V)^{2 / 3}}{A}
$$

where $V$ is the volume of the particle and $A$ is the surface area of a particle. The sphericity (and statistical distribution throughout the sample) indicates the extent to which the constituent particles are spherical (after sintering). The total interfacial area $\left(S_{\text {int,tot }}\right)$ is obtained from the total surface area of the unsegmented copper domain. The segmentation process identifies the necking areas where particles are adjoined, shown as red lines in the 2D images in Fig. 3(e). The total necking area $\left(S_{\text {neck,tot }}\right)$ is obtained by subtracting the total surface area of unsegmented copper domain from that of the segmented copper domain (equivalent to the area of the segmented necks shown in red in Fig. 3(e)). The unit interfacial area $\left(S_{\text {int }}\right)$ and unit necking area $\left(S_{\text {neck }}\right)$ are obtained by normalizing the total interfacial area and total necking area by the total volume of the sample, respectively.

3.4 Mesh Generation. The simpleware +FE module is used for generating meshes of discretized volumes. The number of particles/pores in the scanned 3D volume is computationally intractable for mesh generation and subsequent numerical simulation processes. Hence, a reduced domain size is carefully chosen such that the geometric properties are maintained and the volumetric porosity matches that of the scanned sample; the length and width of each sample are cropped to seven pore lengths. A mesh size of $0.1 \times 10^{6}$ cells per pore is selected based on a mesh-independence study performed on a reduced domain size, which shows a $1.6 \%$ deviation in effective permeability for $0.1 \times 10^{6}$ cells per pore compared to a refined mesh size of $0.3 \times 10^{6}$ cells per pore. The resulting domain sizes and number of mesh elements for each sample are shown in Table 2. The processed 3D volume used for generating meshes consists of $3 \mathrm{D}$ voxels, which would generate a stair-stepped mesh if used directly. Hence, the data are smoothed (as recommended by Ref. [32]) to generate high-quality conformal meshes with tetrahedral elements, ensuring the volume skew limit to be lower than 0.01 . Figure 5 shows the mesh generated for the spherical particle coating at $39 \%$ porosity.

3.5 Numerical Modeling. In order to obtain the effective thermophysical properties of the sintered coatings, viz., permeability and thermal conductivity, the physics modules available in SIMPLEWARE are employed. The primary direction of heat transfer through the sintered coating is in the $z$-direction. Similarly, during boiling, the departure of vapor bubbles and subsequent replenishment of liquid also occurs primarily in this direction. Hence, the effective permeability and conductivity are calculated along the $z$-direction.

The SIMPLEWARE +FLOW module is used to calculate the effective permeability of the pore domain. The governing mass and momentum conservation equations are solved using a minimum residual-based homogenization solver and linear pressure (a)

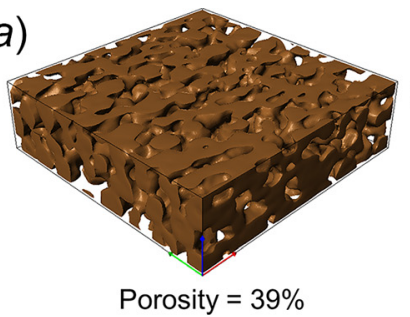

(b)
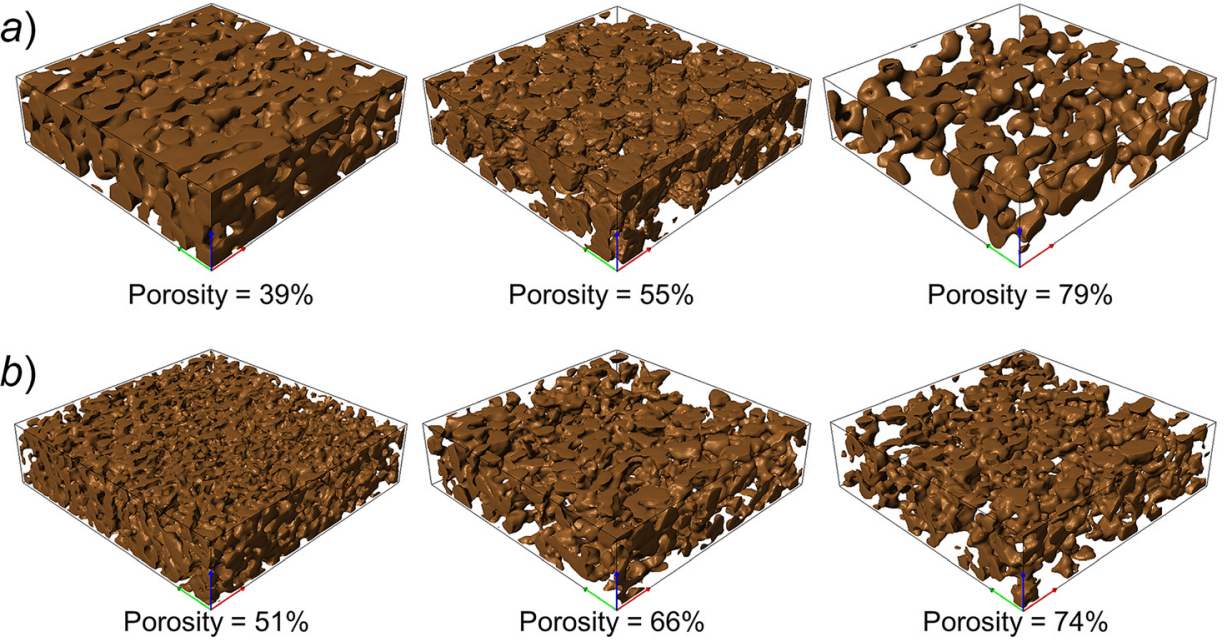

Fig. 4 Three-dimensional reconstructed solid domain (after thresholding) for (a) spherical and $(b)$ irregular coatings at a low, intermediate, and high porosity 
Table 2 Numerical mesh and domain size

\begin{tabular}{lccc}
\hline \hline Particle shape & $\varepsilon(\%)$ & Domain size $x \times y \times z(\mu \mathrm{m} \times \mu \mathrm{m} \times \mu \mathrm{m})$ & Number of cells $\left(\times 10^{6}\right)$ \\
\hline Spherical & 39 & $340 \times 340 \times 207$ & 15.7 \\
& 45 & $480 \times 480 \times 163$ & 10.3 \\
& 55 & $520 \times 520 \times 219$ & 15.4 \\
& 68 & $700 \times 700 \times 219$ & 14.2 \\
& 72 & $720 \times 720 \times 219$ & 14.5 \\
Irregular & 79 & $760 \times 760 \times 203$ & 14.0 \\
& 51 & $340 \times 340 \times 195$ & 20.2 \\
& 58 & $420 \times 420 \times 199$ & 18.6 \\
& 66 & $540 \times 540 \times 199$ & 16.4 \\
& 71 & $620 \times 620 \times 203$ & 16.0 \\
\hline \hline
\end{tabular}

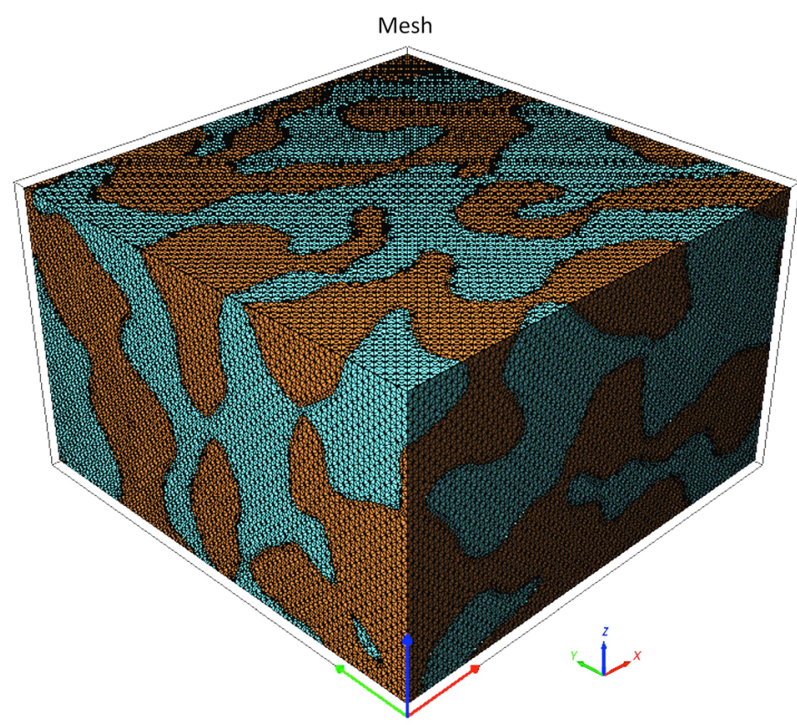

Fig. 5 Meshed domain $(340 \mu \mathrm{m} \times 340 \mu \mathrm{m} \times 207 \mu \mathrm{m})$ for the spherical particle coating at $39 \%$ porosity is shown

variation boundary condition. This boundary condition fixes the pressure on the inlet and outlet faces of the domain such that the pressure drop per unit length between the inlet and outlet faces is one unit. Linear pressure variation is imposed across the lateral faces, which mimics the more conventionally used symmetry boundary condition [32]. These boundary conditions are shown in Fig. $6(a)$. The effective permeability in the flow direction $(z$-direction) is obtained using Darcy's law

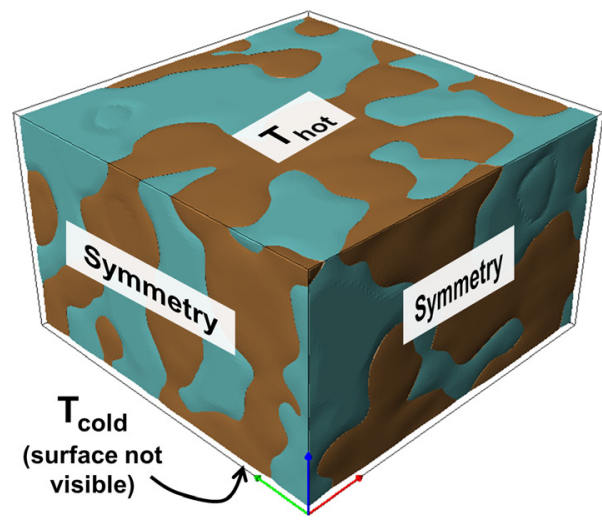

(a)

$$
U=-\frac{K_{z}}{\mu} \nabla p
$$

where $\nabla p$ is the applied pressure gradient and $K_{z}$ is the effective permeability of the medium in the $z$-direction.

The SIMPLEWARE + LAPLACE module is used to calculate the effective thermal conductivity of the liquid-saturated porous medium. The governing Laplace equations for diffusion are solved using the conjugate gradient method for the pore and copper domains individually. For the pore domain, fluid properties of FC-72 at room temperature are used whereas for the solid domain, properties of copper at room temperature are used. A mixed boundary condition is employed that assumes symmetry boundary conditions along the lateral faces and a fixed-temperature boundary at the top and bottom faces such that the temperature difference per unit length between the top and bottom faces is one unit. Continuity of temperature and heat flux is imposed at the pore-solid interface. The boundary conditions are shown in Fig. $6(b)$. The effective thermal conductivity is computed from

$$
q^{\prime \prime}=-k_{z} \frac{\partial T}{\partial Z}
$$

where $q^{\prime \prime}$ is the heat flux on the bottom wall, $\partial T / \partial z$ is the temperature gradient along the $z$-direction, and $k_{z}$ is the effective thermal conductivity of the medium along the $z$-direction.

The physics modules in the software use a finite element-based homogenization solver. The pressure and velocity components are discretized with continuous linear nodal elements. Further details about the solution methods and boundary conditions may be found in Ref. [32].

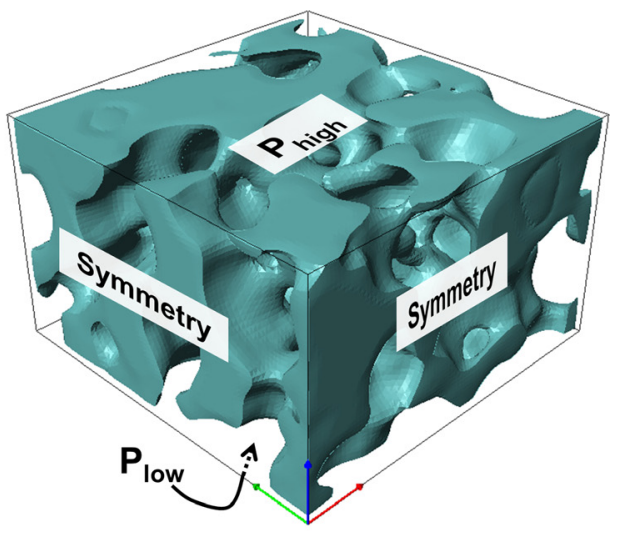

(b)

Fig. 6 Boundary conditions for (a) conduction through copper and pore domains and (b) flow through the pore domain, used to obtain the effective conductivity and effective permeability, respectively 
3.6 Quantitative Regression Analysis. The statistical relationship between the coating characteristics and the boiling performance is analyzed in order to identify critical sensitivities. This is achieved by performing a stepwise regression analysis with multiple inputs in MATLAB [33], tailored to represent the input-output relationship in the present study. The data obtained from the boiling experiments and the coating characterization are divided into three primary categories, viz., geometric coating properties, effective thermophysical coating properties, and boiling performance characteristics. First, the dependence of the effective thermophysical properties on the geometric properties is evaluated (i.e., each effective thermophysical property is treated as an output and the geometric properties are treated as inputs). Subsequently, the dependence of the boiling characteristics on the individual geometric and thermophysical properties is determined (i.e., each boiling characteristic is treated as an output, while the geometric and thermophysical properties are treated as inputs).

A stepwise regression is performed using the stepwiselm function in MATLAB for each input-output pair, using a quadratic polynomial fit. For the quadratic polynomial fit chosen, there can be either a linear or quadratic dependence between each input and output. The stepwise regression uses forward and backward regression to add or remove terms from the model, based on the $p$-value of a term, thus determining whether the dependence for each input-output pair is linear or quadratic. The $R^{2}$ value of the polynomial fit indicates how well the model fits the actual data (better fit as $R^{2}$ approaches unity), while a lower $p$-value indicates a more significant input parameter term $[34,35]$.

In order to study the combined effect of multiple input geometric properties, the most critical input geometric parameters are then selected based on the lowest $p$-values for each output considered. The number of samples tested experimentally limits the number of critical input parameters that can be assessed in combination (maximum of three). A direct regression is then performed using the fitlm function in MATLAB with only the significant terms for each input parameter. The $p$-value and $R^{2}$ value of the resulting dependence are checked for goodness of fit of the significant terms identified. This approach is taken because using a stepwise regression for the final dependence of the combined variable could only identify a smaller number of critical coating parameters, which may not be unique, given the limited number of experimental data points. Hence, after identifying the critical input terms for each output based on the number of experimental data points available (i.e., three critical inputs), a direct regression forces the final model to include all these critical input parameters so as to obtain a combined dependence. It is noted that the $p$-value of the final model should therefore not be compared to that of the individual input-output pairs, but simply used as a stand-alone indicator of the significance of the terms in the final model.

\section{Results and Discussion}

4.1 Boiling Curves. For porous coatings formed from particles of the same size $(90-106 \mu \mathrm{m})$, each distinct particle morphology and porosity creates pores of unique shapes, thereby leading to differences in the boiling heat transfer performance. Figure 7 shows the boiling curves obtained for the irregular and spherical particle coatings described in Table 1.

Compared to a polished surface [9], these sintered surfaces show boiling incipience wall superheat that is 16-80 times lower, peak heat transfer coefficients that are 8-25 times higher, and CHF that is higher by a factor of $1.2-2$. The increased density of active nucleation sites and enhancement of heat transfer area are the primary contributors to the heat transfer coefficient enhancement for such sintered surfaces. The overall trend of the boiling curves is similar to that of typical sintered surfaces. At very low heat fluxes (below $\sim 4 \mathrm{~kW} / \mathrm{m}^{2}$, not shown on the graph), natural convection heat transfer occurs. As the heat flux is increased, nucleate boiling incipience occurs at very low wall superheat $(<1 \mathrm{~K})$. With further increase in heat flux, the wall superheat consistently increases. The heat transfer coefficient, as shown in Fig. 8, is a function of the wall superheat at any given heat flux as is typically observed for pool boiling studies, although the exact variation depends on the individual coating characteristics.

Comparing the boiling curves for the different coating geometries, it is observed that boiling incipience occurs for all of the different coatings at a low superheat $(0.2-1 \mathrm{~K})$ and a heat flux of $\sim 5-9 \mathrm{~kW} /$ $\mathrm{m}^{2}$. As the heat flux is increased beyond incipience, the wall superheat continues to increase. For both spherical and irregular particle coatings, it is observed that the heat transfer coefficient generally decreases with increase of coating porosity throughout the range of porosities investigated $(\sim 40-80 \%)$. For the low-porosity coatings (up to $55 \%$ for spherical and $51 \%$ for irregular), the heat transfer coefficient increases at a rapid rate after incipience, reaches a maximum value, and then decreases at higher heat fluxes (indicated by the increasing and then decreasing slope of the boiling curve). However, increasing the porosity above these porosities alters the nature of the boiling curve. For these higher porosities, heat transfer coefficient increases monotonically as the heat flux increases, as has been
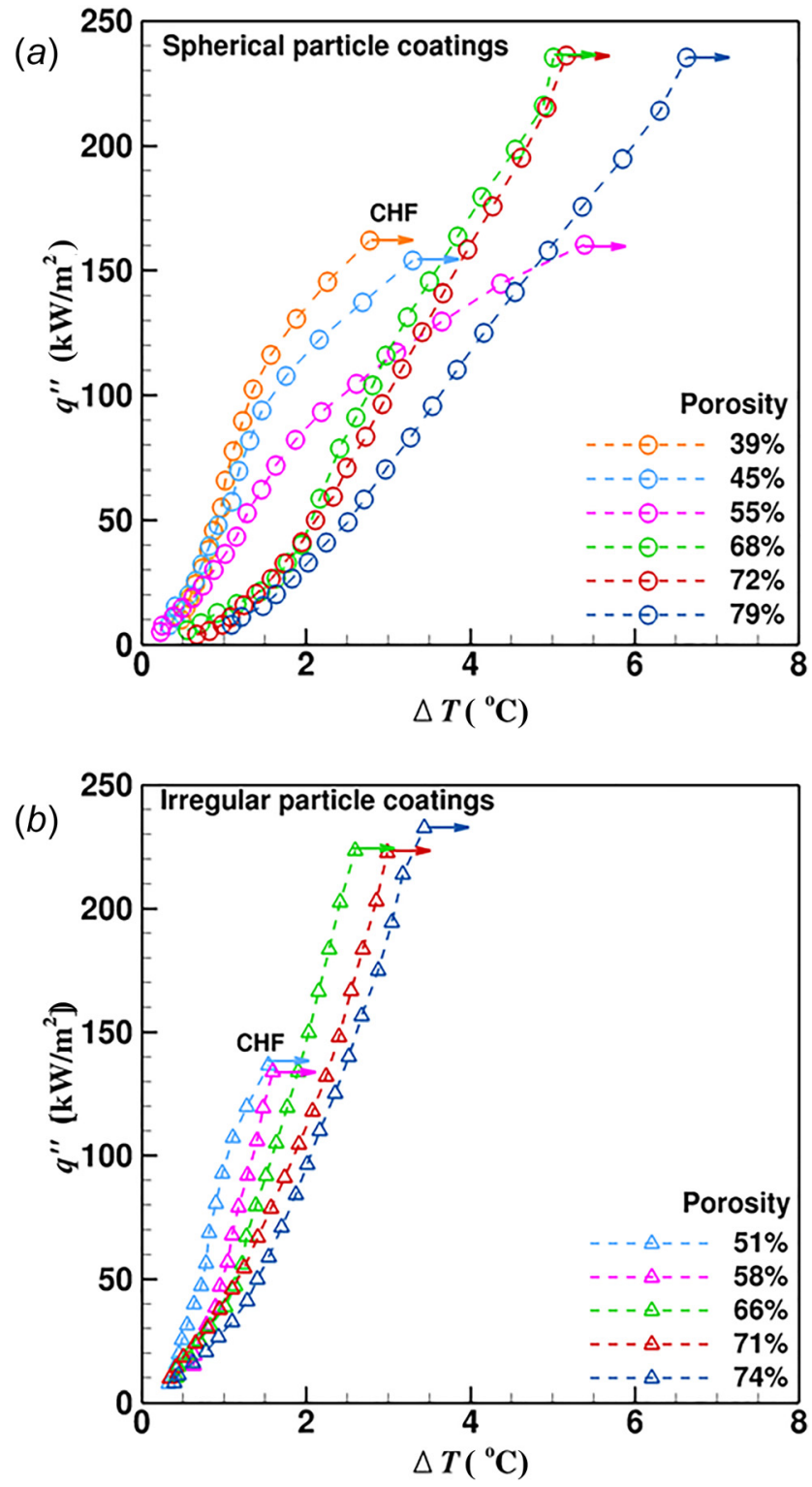

Fig. 7 Boiling curves of area-averaged heat flux versus wall superheat, $\Delta T\left(T_{s}-T_{\text {sat }}\right)$, for (a) spherical and $(b)$ irregular particle coatings. Occurrence of CHF is indicated by horizontal arrows. 


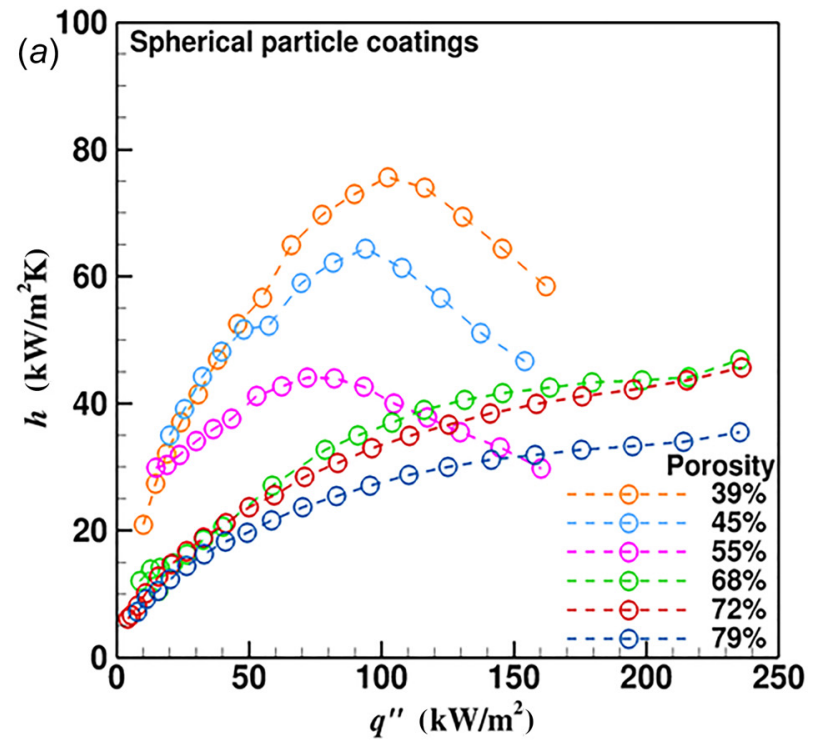

(b)

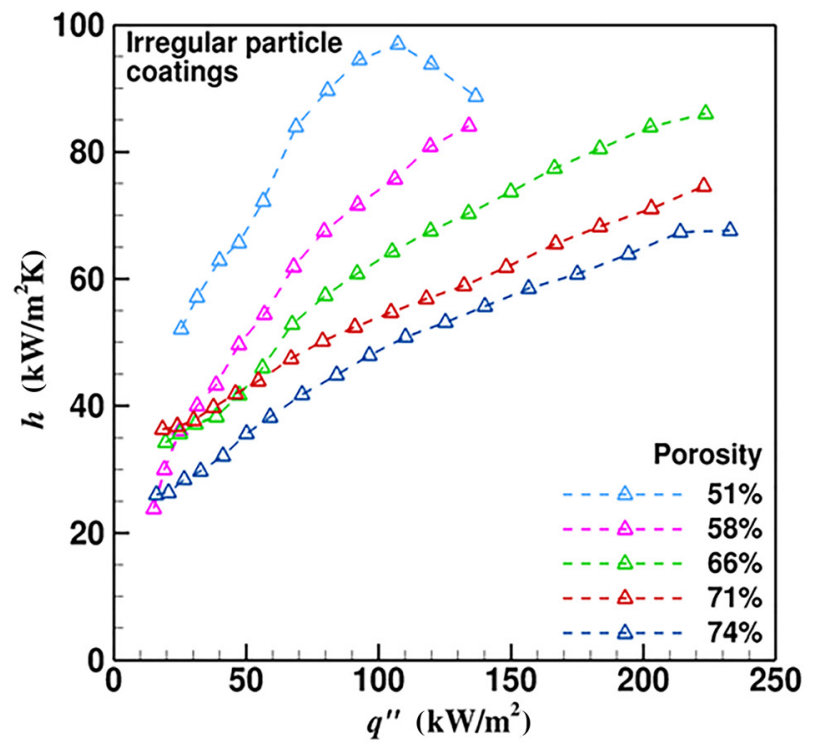

Fig. 8 Heat transfer coefficient versus area-averaged heat flux for $(a)$ spherical and $(b)$ irregular particle coatings

previously observed for sintered spherical coatings [8,36]. The irregular particle coatings show better heat transfer performance (i.e., a lower superheat at a given heat flux, implying a higher heat transfer coefficient) compared to the spherical coatings at similar porosities throughout the boiling curve.

The coating characteristics also have an effect on the CHF. Low-porosity particle coatings generally have a lower CHF than higher-porosity coatings, e.g., irregular particle coatings with porosity $\leq 58 \%$ reach $\mathrm{CHF}$ at $\sim 135 \pm 2 \mathrm{~kW} / \mathrm{m}^{2}$ and spherical particle coatings with porosity $\leq 55 \%$ reach CHF at $\sim 159 \pm 4 \mathrm{~kW} /$ $\mathrm{m}^{2}$. Above these coating porosities, a sudden jump in CHF is observed (to $226 \pm 5 \mathrm{~kW} / \mathrm{m}^{2}$ for irregular particle coatings and $236 \pm 0.4 \mathrm{~kW} / \mathrm{m}^{2}$ for spherical particle coatings).

This drastic change in the behavior of the boiling curve heat transfer coefficient and CHF at a critical porosity value suggests the presence of a corresponding change in some governing coating characteristics at this porosity. The general trends in boiling performance are first qualitatively analyzed in light of the morphology of the sintered particle coatings revealed by the SEM images in Fig. 2, followed by a quantitative analysis of the boiling characteristics in terms of the coating properties evaluated from $\mu$-CT scans.
4.2 Qualitative Image Analysis. It is observed from Fig. 2 that the structure of the open pores and the particle packing arrangement in the sintered coatings depend on the particle morphology and coating porosity. The pores in the irregular particle coatings qualitatively appear smaller and more tortuous than in the case of the spherical particles. Larger pores at similar porosity, as seen in the spherical particle coatings, may be indicative of lesser interfacial area between the liquid in the pores and the copper particles, as well as reduced contact between individual copper particles, thereby reducing the effective thermal conductivity of the coating. It is also clear from the images that the spherical particles have a notably smoother surface compared to the roughness displayed by the irregular particles. This inherent surface roughness likely leads to an enhancement of the interstitial surface area available for heat transport during boiling with the irregular particles at the same porosity. For a fixed particle type, Fig. 2 shows that pore diameters increase with porosity. The heat transfer performance of the coatings is consistent with these qualitative observations regarding the pore size and surface roughness; irregular particles have a higher heat transfer coefficient than spherical particles, and higher porosity coatings have lower heat transfer coefficients.

The pore size also has an effect on the CHF reached by the coatings. Larger pores allow more efficient vapor escape at higher heat fluxes, thereby leading to higher $\mathrm{CHF}$ for coatings with higher porosities, consistent with findings from previous studies $[11,37]$. Between the two particle types, spherical particle coatings have slightly higher $\mathrm{CHF}$ at the same porosity compared to irregular particle coatings, which is consistent with the larger pore size observed in the images.

The pore structure may also explain the observed change in the slope of the boiling curve for the different coating porosities. As the heat flux is increased, the heat transfer coefficient initially increases for all samples. However, as noted in Sec. 4.1, further increases in heat flux reduce the heat transfer coefficient for coating porosities below 55\% (Fig. 8). This behavior may be attributed to inefficient vapor escape and liquid replenishment through these coatings, compared to the behavior with the larger pores at higher coating porosities.

While the SEM images provide qualitative visualization of the pore structure of the coatings, the quantitative characterization presented in Secs. 4.3 and 4.4 is essential to establishing the geometric differences between the coatings, identifying critical parameters that affect the boiling heat transfer performance of sintered particle coatings, and allowing firm conclusions to be drawn about the boiling curve trends on the basis of significant coating characteristics.

4.3 Geometric and Effective Thermophysical Properties of the Coating. The geometric properties of the coatings are obtained from the $\mu$-CT reconstructions as described in Sec. 3.3. Table 3 shows the geometric coating parameters for each particle morphology and porosity investigated, viz., coating porosity $(\varepsilon)$, particle diameter $\left(d_{\text {part }}\right)$ distribution, pore diameter $\left(d_{\text {pore }}\right)$ distribution, sphericity $(\phi)$ distribution, unit interfacial area, $\left(S_{\text {int }}\right)$ and unit necking area $\left(S_{\text {neck }}\right)$. The numerically simulated values of effective permeability $\left(K_{z}\right)$ and effective thermal conductivity $\left(k_{z}\right)$ along the $z$-direction are also shown. The arrows at the bottom of each column indicate whether the property increases or decreases with an increase of coating porosity.

Figure 9 shows representative temperature and pressure contours obtained from the numerical simulations for a spherical particle coating at $39 \%$ porosity and an irregular particle coating at $66 \%$. The temperature and pressure are observed to be stratified along the $z$-direction, as with past observations in the literature [25]. The heat transfer coefficient and CHF for the boiling curves are also shown in Table 3. The heat transfer coefficient $\left(h_{\mathrm{av}}\right)$ is an average value computed over the range of heat fluxes varying from $25 \%$ to $75 \%$ of CHF. This average heat transfer coefficient 
Table 3 Geometric properties, effective thermophysical properties, and boiling performance of the sintered particle coatings investigated. The arrows at the bottom of each column indicate whether the property increases (upward arrow) or decreases (downward arrow) with increase of porosity, for each type of coating.

\begin{tabular}{|c|c|c|c|c|c|c|c|c|c|c|}
\hline \multirow[b]{2}{*}{ Particle shape } & \multicolumn{6}{|c|}{ Geometric properties } & \multicolumn{2}{|c|}{ Effective thermophysical properties } & \multicolumn{2}{|c|}{ Boiling performance } \\
\hline & $\varepsilon(\%)$ & $d_{\text {pore }}(\mu \mathrm{m})$ & $d_{\text {part }}(\mu \mathrm{m})$ & $\phi$ & $S_{\mathrm{in} t}\left(\mathrm{~mm}^{-1}\right)$ & $S_{\text {neck }}\left(\mathrm{mm}^{-1}\right)$ & $K_{z}\left(\times 10^{-5} \mathrm{~mm}^{2}\right)$ & $k_{z}(\mathrm{~W} / \mathrm{m} \mathrm{K})$ & $h_{\mathrm{av}}\left(\mathrm{kW} / \mathrm{m}^{2} \mathrm{~K}\right)$ & $\mathrm{CHF}\left(\mathrm{kW} / \mathrm{m}^{2}\right)$ \\
\hline \multirow[t]{7}{*}{ Spherical } & 39 & $48 \pm 24$ & $85 \pm 18$ & $0.79 \pm 0.11$ & 74 & 12.4 & 1.6 & 129 & 66.6 & 162 \\
\hline & 45 & $65 \pm 27$ & $80 \pm 17$ & $0.73 \pm 0.16$ & 72 & 9.5 & 3.5 & 105 & 56.9 & 154 \\
\hline & 55 & $73 \pm 31$ & $84 \pm 17$ & $0.70 \pm 0.09$ & 63 & 8.1 & 7.7 & 78.3 & 41.3 & 160 \\
\hline & 68 & $96 \pm 52$ & $77 \pm 15$ & $0.75 \pm 0.1$ & 34 & 5.4 & 31.2 & 40.3 & 36.9 & 235 \\
\hline & 72 & $104 \pm 50$ & $79 \pm 22$ & $0.79 \pm 0.12$ & 30 & 2.8 & 33.1 & 29.3 & 34.3 & 236 \\
\hline & 79 & $107 \pm 59$ & $77 \pm 15$ & $0.79 \pm 0.11$ & 27 & 2.2 & 41.8 & 16.9 & 28.0 & 235 \\
\hline & $\uparrow$ & $\uparrow$ & 一 & - & $\downarrow$ & $\downarrow$ & $\uparrow$ & $\downarrow$ & $\downarrow$ & $\uparrow$ \\
\hline \multirow[t]{6}{*}{ Irregular } & 51 & $52 \pm 199$ & $75 \pm 17$ & $0.57 \pm 0.09$ & 84 & 12.9 & 1.6 & 141 & 78.2 & 137 \\
\hline & 58 & $61 \pm 24$ & $73 \pm 16$ & $0.60 \pm 0.22$ & 73 & 8.3 & 1.8 & 86.6 & 63.5 & 134 \\
\hline & 66 & $78 \pm 32$ & $71 \pm 14$ & $0.70 \pm 0.10$ & 54 & 5.5 & 6.9 & 54.1 & 59.4 & 223 \\
\hline & 71 & $85 \pm 39$ & $69 \pm 14$ & $0.74 \pm 0.15$ & 47 & 4.3 & 11.1 & 42.7 & 55.9 & 223 \\
\hline & 74 & $94 \pm 42$ & $70 \pm 14$ & $0.71 \pm 0.10$ & 43 & 3.9 & 17.6 & 37.5 & 48.9 & 233 \\
\hline & $\uparrow$ & $\uparrow$ & - & - & $\downarrow$ & $\downarrow$ & $\uparrow$ & $\downarrow$ & $\downarrow$ & $\uparrow$ \\
\hline
\end{tabular}

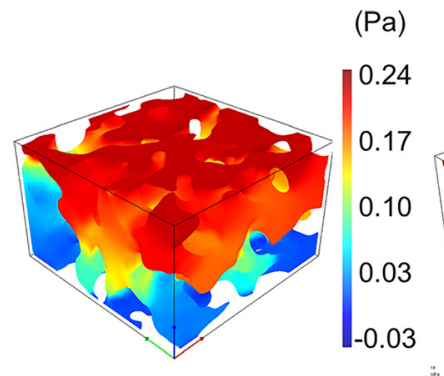

(a)

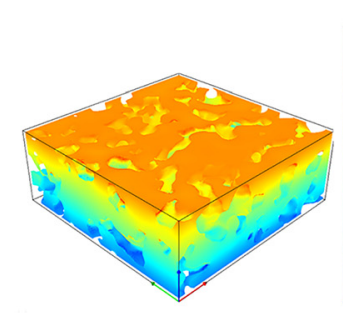

(d)

Pore domain

(Pa)

(Pa)
0.24
0.17
0.10
0.03
-0.03

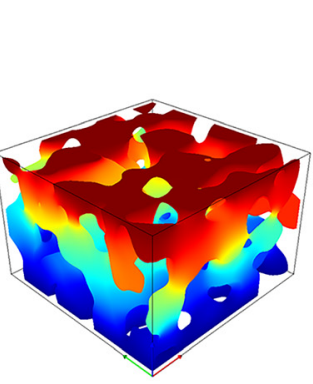

(b)
(K)

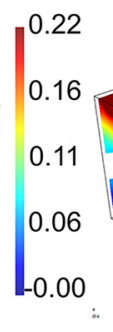

:

(K)

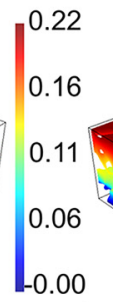

(K)

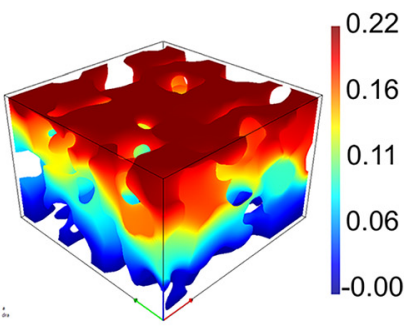

(c) (e)

Solid domain

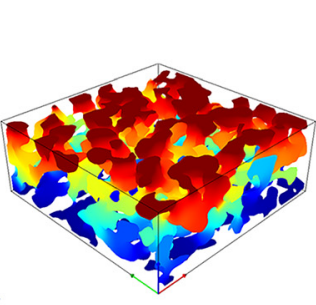

0.22

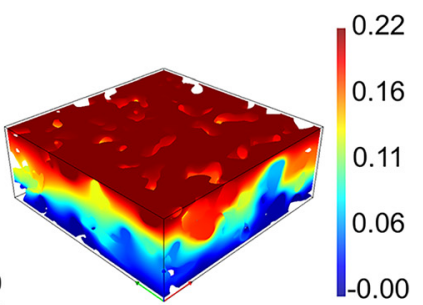

(c)

Pore domain

Fig. 9 Representative contours of (a) pressure field in the pore domain, $(b)$ temperature field in the solid domain, and $(c)$ temperature field in the pore domain for the spherical particle coating at $39 \%$ porosity. The corresponding contours for irregular particle coatings at $66 \%$ porosity are shown in $(d-f)$. The contours are obtained from numerical simulation of the effective permeability and effective thermal conductivity.

is merely an indicative representation of the heat transfer coefficient provided by the coating across much of the boiling curve.

It may be noted here that while all coatings were fabricated using loose particles sieved to the same size range $(90-106 \mu \mathrm{m})$, the average particle diameters are reduced upon sintering, and are observed to be of the same order, of $\sim 70-85 \mu \mathrm{m}$. The sphericity of the coatings is also observed to be fairly constant over the range of porosities investigated. The irregular particle coatings show a slightly smaller average sphericity compared to the spherical particle coatings. The sphericity is indicative of the qualitative morphological differences between the two types of coatings formed by spherical and irregular particles.

For both spherical and irregular coatings, the average pore diameter increases with an increase in the coating porosity (from $\sim 50 \mu \mathrm{m}$ to $\sim 100 \mu \mathrm{m}$ over the porosity rage), as was observed qualitatively from the SEM images. The average pore size (as well as the standard deviation) shows a gradual increase with porosity up to an intermediate value (55\% for spherical and 58\% for irregular particle coatings), followed by a sharp increase. This quantitative characterization is consistent with the drastic change in the trends of the boiling heat transfer coefficient and CHF noted at this intermediate porosity, as was described in Sec. 4.1. This sharp increase may be attributed to the large increase in the percentage of carbonate particles from $10 \%$ to $45 \%$ that was necessary to achieve the desired higher porosity. While for low carbonate percentages $(\sim 0-10 \%)$, the pore size may be dominated by the size of copper particles, the pores formed at higher carbonate percentages may be determined by both the carbonate and the 
Table 4 Analysis of the relationship between geometric coating properties and the effective thermophysical properties. The critical input properties affecting each output are shown underlined and bold.

\begin{tabular}{|c|c|c|c|c|c|c|c|}
\hline \multirow[b]{2}{*}{$\begin{array}{l}\text { Effective thermophysical } \\
\text { property }\end{array}$} & \multirow[b]{2}{*}{$\begin{array}{c}\text { Input geometric } \\
\text { property }\end{array}$} & \multicolumn{3}{|c|}{ Spherical particle coating } & \multicolumn{3}{|c|}{ Irregular particle coating } \\
\hline & & $\begin{array}{l}\text { Variable } \\
\text { dependence }\end{array}$ & $R^{2}$ & $\begin{array}{l}p \text {-value } \\
\left(\times 10^{-3}\right)\end{array}$ & $\begin{array}{l}\text { Variable } \\
\text { dependence }\end{array}$ & $R^{2}$ & $\begin{array}{l}p \text {-value } \\
\left(\times 10^{-3}\right)\end{array}$ \\
\hline \multirow[t]{8}{*}{ Permeability, $K_{z}\left(\mathrm{~mm}^{2}\right)$} & $\varepsilon$ & $f\left(\varepsilon^{2}\right)$ & 0.96 & 0.34 & $f\left(\varepsilon^{2}\right)$ & 0.98 & 12.7 \\
\hline & $d_{\text {pore }}$ & $f\left(d_{\text {pore }}^{2}\right)$ & 0.95 & 0.55 & $f\left(d_{\text {pore }}^{2}\right)$ & 1 & 5.4 \\
\hline & $\overline{S_{\text {int }}}$ & $f\left(S^{2}{ }_{\mathrm{int}}\right)$ & 0.99 & 0.86 & $f\left(S^{2}{ }_{\text {int }}\right)$ & 0.94 & 30.3 \\
\hline & $S_{\text {neck }}$ & $f\left(S_{\text {neck }}\right)$ & 0.88 & 3.5 & $f\left(S_{\text {neck }}\right)$ & 0.56 & 90.7 \\
\hline & $d_{\text {part }}$ & $f\left(d_{\text {part }}\right)$ & 0.63 & 37 & $f\left(d_{\text {part }}\right)$ & 0.56 & 89.8 \\
\hline & $\sigma_{\underline{d \text { pore }}}$ & $f\left(\sigma_{d \text { pore }}\right)$ & 0.99 & 0.02 & $f\left(\sigma_{d \text { pore }}\right)$ & 0.87 & 12.9 \\
\hline & $\Phi$ & $f(\phi$ & 0.04 & 333 & $f(\phi)$ & 0.55 & 92.5 \\
\hline & $\varepsilon, d_{\text {pore }}, \sigma_{d \text { pore }}$ & $f\left(\varepsilon^{2}, d_{\text {pore }}^{2}, \sigma_{d \text { pore }}\right)$ & 0.99 & 8.6 & $f\left(\varepsilon^{2}, d_{\text {pore }}^{2}, \sigma_{d \text { pore }}\right)$ & 0.96 & 120 \\
\hline \multirow{8}{*}{ Thermal conductivity, $k_{z}(\mathrm{~W} / \mathrm{m} \mathrm{K})$} & $\varepsilon$ & $f(\varepsilon)$ & 0.99 & 0.02 & $f(\varepsilon)$ & 0.91 & 6.5 \\
\hline & $d_{\text {pore }}$ & $f\left(d^{2}\right.$ pore $)$ & 0.98 & 0.91 & $f\left(d_{\text {pore }}^{2}\right)$ & 0.96 & 19.2 \\
\hline & $S_{\text {int }}$ & $F\left(S^{2}{ }_{\text {int }}\right)$ & 0.95 & 0.54 & $f\left(S^{2}{ }_{\text {int }}\right)$ & 0.95 & 2.8 \\
\hline & $\overline{\underline{S_{\text {neck }}}}$ & $f\left(S_{\text {neck }}\right)$ & 0.97 & 0.22 & $f\left(S_{\text {neck }}\right)$ & 1 & 0.01 \\
\hline & $\overline{d_{\text {part }}}$ & $f\left(d_{\text {part }}\right)$ & 0.57 & 52 & $f\left(d_{\text {part }}\right)$ & 0.90 & 8.6 \\
\hline & $\sigma_{d \mathrm{pore}}$ & $f\left(\sigma_{d \text { pore }}\right)$ & 0.92 & 1.4 & $f\left(\sigma_{d \text { pore }}\right)$ & 0.84 & 18.6 \\
\hline & $\Phi$ & $f(\phi)$ & 0.16 & 599 & $f(\phi)$ & 0.83 & 20.8 \\
\hline & $\varepsilon, S_{\text {neck }}, S_{\text {int }}$ & $f\left(\varepsilon, S_{\text {neck }}, S^{2}{ }_{\text {int }}\right)$ & 0.99 & 5.8 & $f\left(\varepsilon, S_{\text {neck }}, S_{\text {int }}^{2}\right)$ & 1 & 24.5 \\
\hline
\end{tabular}

copper particle sizes, and hence show a wider size distribution. Coatings with higher porosity and pore sizes are also shown to have higher permeability values in Table 3 . Since permeability indicates the ease with which fluid can pass through the coating, higher permeability leads to more efficient vapor escape, resulting in a higher CHF. This is in accordance with the observations above, where coatings with a higher porosity or pore size show a drastic increase in CHF due to the associated higher permeability. Irregular particle coatings which have smaller pore sizes also have lower permeability, and hence, lower CHF than spherical particle coatings at similar porosity. While measuring the bulk coating characteristics such as porosity may provide insight into the general trends of the boiling performance, it is insufficient to explain the finer differences such as the drastic change in CHF, which is more clearly explained from the pore structure analysis. Hence, a high-fidelity characterization of the pore statistics is essential to interpreting the boiling performance of the coatings, as is performed herein.

The unit interfacial area $\left(S_{\text {int }}\right)$ of the sintered particle coatings denotes the surface area available for heat transfer between the solid and fluid domains during boiling, while the unit necking area $\left(S_{\text {neck }}\right)$ indicates the contact area available for solid-solid conduction between individual copper particles. For both spherical and irregular particle coatings, an increase in porosity is associated

Table 5 Analysis of the relationship between the geometric and effective thermophysical properties on boiling performance characteristics. The critical input properties affecting each output are shown underlined and bold.

\begin{tabular}{|c|c|c|c|c|c|c|c|c|}
\hline \multirow[b]{2}{*}{$\begin{array}{l}\text { Boiling } \\
\text { performance }\end{array}$} & \multirow[b]{2}{*}{$\begin{array}{c}\text { Input } \\
\text { variable type }\end{array}$} & \multirow[b]{2}{*}{$\begin{array}{l}\text { Input geometric } \\
\text { parameter }\end{array}$} & \multicolumn{3}{|c|}{ Spherical particle coating } & \multicolumn{3}{|c|}{ Irregular particle coating } \\
\hline & & & $\begin{array}{c}\text { Variable } \\
\text { dependence }\end{array}$ & $R^{2}$ & $\begin{array}{l}p \text {-value } \\
\left(\times 10^{-3}\right)\end{array}$ & $\begin{array}{c}\text { Variable } \\
\text { dependence }\end{array}$ & $R^{2}$ & $\begin{array}{c}p \text {-value } \\
\left(\times 10^{-3}\right)\end{array}$ \\
\hline \multirow{10}{*}{$\begin{array}{l}\text { Average heat } \\
\text { transfer coefficient, } \\
h_{\mathrm{av}}\left(\mathrm{kW} / \mathrm{m}^{2} \mathrm{~K}\right)\end{array}$} & \multirow[t]{8}{*}{ Geometric property } & $\varepsilon$ & $f(\varepsilon)$ & 0.96 & 0.31 & $f(\varepsilon)$ & 0.96 & 2.6 \\
\hline & & $d_{\text {pore }}$ & $f\left(d_{\text {pore }}\right)$ & 0.94 & 0.79 & $f\left(d_{\text {pore }}\right)$ & 0.91 & 7.6 \\
\hline & & $\overline{S_{\mathrm{int}}}$ & $f\left(S^{2}{ }_{\text {int }}\right)$ & 0.92 & 9.9 & $f\left(S^{2}{ }_{\mathrm{int}}\right)$ & 0.92 & 42.5 \\
\hline & & $\underline{S_{\text {neck }}}$ & $f\left(S_{\text {neck }}\right)$ & 0.92 & 1.5 & $f\left(S_{\text {neck }}\right)$ & 0.98 & 1.0 \\
\hline & & $\overline{d_{\text {part }}}$ & $f\left(d_{\text {part }}\right)$ & 0.56 & 88.4 & $f\left(d_{\text {part }}\right)$ & 0.87 & 13.1 \\
\hline & & $\sigma_{d \mathrm{pore}}$ & $f\left(\sigma_{d \text { pore }}\right)$ & 0.85 & 5.3 & $f\left(\sigma_{d \text { pore }}\right)$ & 0.90 & 9.3 \\
\hline & & $\phi$ & $f(\phi)$ & 0.21 & 738 & $f(\phi)$ & 0.77 & 32.4 \\
\hline & & $\varepsilon, d_{\text {pore }}, S_{\text {neck }}$ & $f\left(\varepsilon, d_{\text {pore }}, S_{\text {neck }}\right)$ & 0.93 & 39.5 & $f\left(\varepsilon, d_{\text {pore }}, S_{\text {neck }}\right)$ & 0.96 & 114 \\
\hline & \multirow{2}{*}{$\begin{array}{l}\text { Effective thermo- } \\
\text { physical property }\end{array}$} & $K_{z}$ & $f\left(K_{z}\right)$ & 0.84 & 6.8 & $f\left(K_{z}\right)$ & 0.67 & 56.2 \\
\hline & & $\underline{\boldsymbol{k}_{z}}$ & $f\left(k_{z}\right)$ & 0.98 & 0.13 & $f\left(k_{z}\right)$ & 0.97 & 1.20 \\
\hline \multirow{10}{*}{$\begin{array}{l}\text { Critical heat flux, } \\
\text { CHF }\left(\mathrm{kW} / \mathrm{m}^{2}\right)\end{array}$} & \multirow[t]{8}{*}{ Geometric property } & $\underline{E}$ & $f(\varepsilon)$ & 0.80 & 10.1 & $f(\varepsilon)$ & 0.81 & 23.6 \\
\hline & & $d_{\text {pore }}^{-}$ & $f\left(d_{\text {pore }}\right)$ & 0.80 & 9.8 & $f\left(d_{\text {pore }}\right)$ & 0.85 & 16.5 \\
\hline & & $S$ & $f\left(S_{\text {int }}\right)$ & 0.95 & 0.59 & $f\left(S_{\text {int }}\right)$ & 0.88 & 11.4 \\
\hline & & $\overline{S_{\text {neck }}}$ & $f\left(S_{\text {neck }}\right)$ & 0.74 & 18.2 & $f\left(S_{\text {neck }}\right)$ & 0.71 & 47.6 \\
\hline & & $d_{\text {part }}$ & $f\left(d_{\text {part }}\right)$ & 0.58 & 48.6 & $f\left(d_{\text {part }}\right)$ & 0.75 & 37.4 \\
\hline & & $\sigma_{d \text { pore }}$ & $f\left(\sigma_{d \text { pore }}\right)$ & 0.91 & 1.9 & $f\left(\sigma_{d \text { pore }}\right)$ & 0.81 & 25 \\
\hline & & $\Phi$ & $f\left(\phi^{2}\right)$ & 0.10 & 539 & $f\left(\phi^{2}\right)$ & 0.86 & 71.8 \\
\hline & & $\varepsilon, d_{\text {pore }}, S_{\text {int }}$ & $f\left(\varepsilon, d_{\text {pore }}, S_{\text {int }}\right)$ & 0.99 & 2.4 & $f\left(\varepsilon, d_{\text {pore }}, S_{\text {int }}\right)$ & 0.99 & 55.6 \\
\hline & \multirow{2}{*}{$\begin{array}{l}\text { Effective thermo- } \\
\text { physical property }\end{array}$} & $\underline{K_{z}}$ & $f\left(K_{z}^{2}\right)$ & 0.93 & 8.8 & $f\left(K_{z}^{2}\right)$ & 0.91 & 46 \\
\hline & & $\overline{k_{z}}$ & $f\left(k_{z}\right)$ & 0.79 & 10.8 & $f\left(k_{z}\right)$ & 0.70 & 49.2 \\
\hline
\end{tabular}


with a reduction in $S_{\text {int }}$ as well as $S_{\text {neck }}$, as shown in Table 3. At similar porosities, spherical particle coatings have smaller $S_{\text {int }}$ compared to irregular particle coatings, owing to the smoother particle surfaces, as seen from an observation of the SEM images in Sec. 4.2. Spherical particle coatings also have smaller $S_{\text {neck }}$, compared to irregular particle coatings. A larger interfacial area within the coating layer can be more efficiently utilized when the necking area is large; this combination leads to a higher effective thermal conductivity and heat transfer coefficient. Across all the samples considered, coatings with a lower porosity or with irregular particles definitively exhibit higher heat transfer coefficients than those with a higher porosity or with spherical particles (as also observed in Sec. 4.1), due to the larger interfacial and necking areas (and higher thermal conductivities) associated.

4.4 Quantitative Analysis of the Dependence of Boiling Curves on Coating Properties. Section 4.3 described trends in the boiling heat transfer coefficient and critical heat flux with the geometric and effective thermophysical coating properties. While the trends with respect to each property have been qualitatively identified, a modified stepwise regression analysis is now performed to quantify the relative dependence of the boiling performance on each property, and to identify the critical coating properties to which the boiling performance is most sensitive.

To analyze the effect of geometric properties on the effective thermophysical properties (permeability $K_{z}$ and thermal conductivity $k_{z}$ ) of the coatings, each geometric parameter is first treated as a single input with the thermophysical property as an output. The standard deviation of pore size differs significantly across the coatings; hence, it is treated as an individual input parameter $\left(\sigma_{\text {dpore }}\right)$ that could affect the coating performance independent of the pore size itself. Based on the stepwise regression analysis described in Sec. 3.6, the best-match relationship (i.e., linear or quadratic) between the inputs and output is identified, as are the critical input parameters with lowest $p$-values (indicated in bold in Table 4). The function " $f$ " in Table 4 represents the dependence of each output on the input parameters and takes a linear form (i.e., $f(x)=\mathrm{A} x+\mathrm{B}$ ) or quadratic form (i.e., $f(x)=\mathrm{C} x^{2}+\mathrm{D} x+\mathrm{E}$ ), depending on the results of the stepwise regression. For $K_{z}$, the lowest $p$-values are observed for porosity, pore size, and standard deviation of pore size, deemed to be the most significant factors in determining the effective permeability. This is in accordance with the literature, which shows a strong dependence of permeability on coating porosity from the classical Kozeny-Carman relation, Eq. (1), and several variations on this equation [38-40] that identify the pore structure characteristics (such as pore size distribution) as a critical factor affecting permeability. The permeability $K_{z}$ in the present work is observed to show quadratic variation with $\varepsilon$ and $d_{\text {pore }}$, and linear variation with $\sigma_{d \text { pore }}$ for both particle types. To determine the final dependence of the combined variables, a direct regression is then performed using only the critical input terms $\varepsilon^{2}, d_{\text {pore }}^{2}$ and $\sigma_{\text {dpore }}$, which results in a low $p$-value and high $R^{2}$ value as shown in Table 4. Following the same analysis, the most significant factors in determining the effective thermal conductivity are observed to be $\varepsilon$ and $S_{\text {neck }}$ (linear relationship), as well as $S_{\text {int }}$ (quadratic relationship). The thermal conductivity of coatings would be expected to vary with coating porosity [39-43] as well as the unit necking area [25], thus supporting the validity of the method used in the present study. The $p$-value and $R^{2}$ value of the resulting functions are shown in Table 4 and are indicative of the goodness of fit of the significant terms. It is important to note that, while the $p$-value demonstrates the relative significance of the inputs within one dataset, the exact magnitudes cannot be compared between two statistically different datasets, i.e., spherical and irregular particle coatings.

The dependence of effective permeability $K_{z}$ and thermal conductivity $k_{z}$ on the geometric coating properties is fairly well established in the literature $[17,18,25]$. However, there are no unified models depicting the dependence of boiling performance metrics on the geometric and thermophysical coating properties. The regression analysis approach is extended to quantitatively establish this dependence of the heat transfer coefficient and CHF on the coating properties, as shown in Table 5, with critical inputs shown in bold. The variation of $h_{\mathrm{av}}$ with the normalized critical input properties is shown in Fig. 10. Each input property is normalized based on its maximum value for each type of coating. It is demonstrated that $h_{\text {av }}$ is most significantly affected by the geometric properties $\varepsilon, d_{\text {pore }}$, and $S_{\text {neck }}$ (all linear-dependence relationships), as also observed qualitatively in Sec. 4.3 and indicated in bold in Table 5. The effective thermal conductivity $k_{z}$, which is directly dependent on these geometric properties as discussed in Sec. 4.3 , is shown to be the most significant thermophysical property affecting the average heat transfer coefficient linearly.

As shown in Table 5, CHF is observed to vary linearly with the key parameters $\varepsilon, d_{\text {pore }}$ and $S_{\text {int }}$. This agrees with the discussion in Sec. 4.3 , where $\varepsilon$ and $d_{\text {pore }}$ were observed to affect the effective permeability $K_{z}$ (also shown to be the most significant thermophysical property affecting CHF of the coatings), which likely
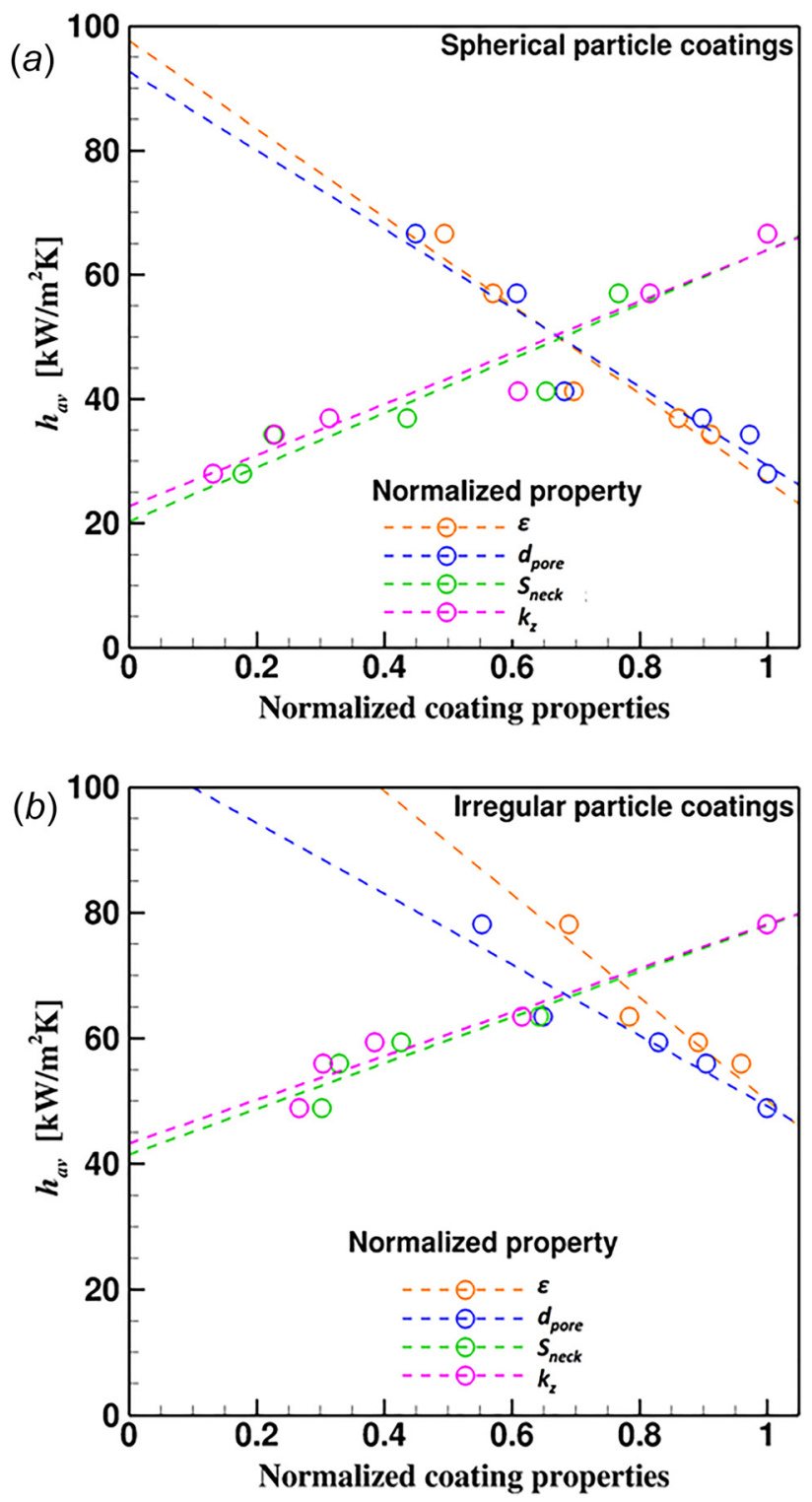

Fig. 10 Heat transfer coefficient versus normalized critical coating properties for (a) spherical and (b) irregular particle coatings. Each input property is normalized by its maximum value. The symbols indicate experimental data points, while the dotted lines indicate a linear fit to the data. 
determines vapor escape and hence CHF of the coatings. While the effect of $S_{\text {int }}$ on CHF may not be intuitive, all the geometric parameters are not truly independent. The value of $S_{\text {int }}$ is dependent on both $\varepsilon$ and $d_{\text {pore }}$ as observed qualitatively, and hence, the cumulative effect likely enhances its influence on CHF.

\section{Conclusion}

The effects of coating characteristics on pool boiling heat transfer performance are investigated for porous coatings formed by sintering copper particles of two different morphologies, viz., irregular and spherical, for particle sizes of $90-106 \mu \mathrm{m}$ over a wide range of coating porosities (40-80\%). Image analysis of the coatings is performed using SEM images and $\mu$-CT scans to obtain qualitative and quantitative characteristics of the coating geometry. Numerical simulation of transport in the reconstructed 3D coatings is performed to obtain the effective thermophysical properties of the coatings. The dependence of the heat transfer coefficient and $\mathrm{CHF}$ on the geometric and thermophysical coating properties is quantitatively determined using a modified stepwise regression analysis.

The boiling heat transfer performance for the coatings is observed to be strongly dependent on the observed differences in the structure of the interstitial pores formed in each coating. The coating porosity, pore diameter, unit necking area, effective thermal conductivity, and effective permeability are observed to be the most critical coating properties affecting the boiling heat transfer coefficient of the coatings. The CHF of the coatings is most strongly affected by the coating porosity, pore diameter, unit interfacial area, effective permeability, and effective conductivity. The coatings with lower porosities or irregular particles show larger heat transfer coefficients along the boiling curve compared to coatings with higher porosities or spherical particles. A sharp shift in the nature of the boiling curve and CHF is observed at an intermediate porosity. The boiling curve characteristics depend strongly on the particle morphology, coating pore structure, and effective thermophysical properties of the coated layer, which can vary widely even for coatings having similar porosity. The bulk coating porosity is inadequate to explain this sharp change in boiling curve behavior, but this trend is clearly explained in terms of the coating pore size distribution, interfacial area, necking area, effective permeability, and effective thermal conductivity obtained from high-fidelity characterization of the pore statistics using $\mu$-CT image analysis. This characterization approach is demonstrated to provide essential insight into the dependence of boiling curve metrics on critical coating properties.

\section{Acknowledgment}

Funding for this work from the Cooling Technologies Research Center, an NSF I/UCRC at Purdue University, is gratefully acknowledged. The authors thank Steve Titolo at Thermophysical Properties Research Laboratory Inc. (TPRL) for assistance with fabrication of the sintered surfaces, Dr. Xuemei Chen and Kevin Drummond for acquiring the SEM images in the Birck Nanotechnology Center at Purdue University, and Dr. James Williams at Indiana University School of Medicine for providing the $\mu$-CT scans. The authors also thank Simpleware Ltd. for providing licensed software usage of the software, and specifically Tom Spirka for his valuable guidance.

\section{Nomenclature}

$$
\begin{aligned}
A & =\text { surface area of a particle, } \mathrm{m}^{2} \\
C & =\text { shape factor } \\
c_{p} & =\text { specific heat capacity, } \mathrm{J} / \mathrm{kg} \mathrm{K} \\
d & =\text { particle diameter, } \mathrm{m} \\
d_{\text {part }} & =\text { particle diameter after sintering, } \mathrm{m} \\
d_{\text {pore }} & =\text { pore diameter after sintering, } \mathrm{m}
\end{aligned}
$$

$h_{\mathrm{av}}=$ average heat transfer coefficient, $\mathrm{kW} / \mathrm{m}^{2} \mathrm{~K}$

$h_{f g}=$ latent heat, $\mathrm{kJ} / \mathrm{kg}$

$k=$ thermal conductivity, $\mathrm{W} / \mathrm{m} \mathrm{K}$

$K=$ permeability, $\mathrm{m}^{2}$

$P=$ applied pressure, $\mathrm{Pa}$

$q^{\prime \prime}=$ wall heat flux, $\mathrm{kW} / \mathrm{m}^{2}$

$S_{\text {int,tot }}=$ total interfacial area of unsegmented particles, $\mathrm{mm}^{2}$

$S_{\text {neck,tot }}=$ total neck area between connected particles, $\mathrm{mm}^{2}$

$S_{\text {int }}=$ total interfacial area of unsegmented particles per unit volume, $\mathrm{mm}^{-1}$

$S_{\text {neck }}=$ total neck area between connected particles per unit volume, $\mathrm{mm}^{-1}$

$T=$ temperature, ${ }^{\circ} \mathrm{C}$

$U=$ average fluid velocity

$V=$ volume of a particle, $\mathrm{m}^{3}$

\section{Greek Symbols}

$\gamma=$ surface tension, $\mathrm{N} / \mathrm{m}$

$\delta=$ coating thickness, $\mathrm{m}$

$\varepsilon=$ porosity

$\mu=$ dynamic viscosity, $\mathrm{kg} / \mathrm{m} \mathrm{s}$

$\rho=$ density, $\mathrm{kg} / \mathrm{m}^{3}$

$\sigma_{\text {dpore }}=$ standard deviation in pore diameter, $\mathrm{m}$

$\phi=$ sphericity

\section{Subscripts}

$$
\begin{aligned}
s & =\text { surface } \\
\text { sat } & =\text { saturation } \\
z & =\text { coordinate direction }
\end{aligned}
$$

\section{References}

[1] Milton, R. M., 1968, "Heat Exchange System," U.S. Patent No. 3384154

[2] Liter, S. G., and Kaviany, M., 2001, "Pool-Boiling CHF Enhancement by Modulated Porous-Layer Coating: Theory and Experiment," Int. J. Heat Mass Transfer, 44(22), pp. 4287-4311.

[3] O' Connor, J. P., and You, S. M., 1995, "A Painting Technique to Enhance Pool Boiling Heat Transfer in Saturated FC-72," ASME J. Heat Transfer, 117(2), p. 387.

[4] You, S. M., and Simon, T. W., 1992, "A Technique for Enhancing Boiling Heat Transfer With Application to Cooling of Electronic Equipment," IEEE Trans. Compon. Hybrids Manuf. Technol., 15(5), pp. 823-831.

[5] El-Genk, M. S., and Parker, J. L., 2005, "Enhanced Boiling of HFE-7100 Dielectric Liquid on Porous Graphite," Energy Convers. Manage., 46(15-16), pp. $2455-2481$.

[6] Parker, J. L., and El-Genk, M. S., 2005, "Enhanced Saturation and Subcooled Boiling of FC-72 Dielectric Liquid," Int. J. Heat Mass Transfer, 48(18), pp. 3736-3752.

[7] Nishikawa, K., Ito, T., and Tanaka, K., 1979, "Enhanced Heat Transfer by Nucleate Boiling on a Sintered Metal Layer," Heat Transfer-Jpn. Res., 8(2), pp. 65-81.

[8] Ranjan, R., Murthy, J. Y., and Garimella, S. V., 2012, "Bubble Dynamics During Capillary-Fed Nucleate Boiling in Porous Media," 13th IEEE Intersociety Conference on Thermal and Thermomechanical Phenomena in Electronic Systems (ITherm), San Diego, CA, pp. 1114-1126.

[9] Sarangi, S., Weibel, J. A., and Garimella, S. V., 2015, "Effect of Particle Size on Surface-Coating Enhancement of Pool Boiling Heat Transfer," Int. J. Heat Mass Transfer, 81, pp. 103-113.

[10] Furberg, R., and Palm, B., 2011, "Boiling Heat Transfer on a Dendritic and Micro-Porous Surface in R134a and FC-72," Appl. Therm. Eng., 31(15), pp. 3595-3603.

[11] O' Hanley, H., Coyle, C., Buongiorno, J., McKrell, T., Rubner, M., and Cohen, R., 2013, "Separate Effects of Surface Roughness, Wettability, and Porosity on the Boiling Critical Heat Flux," Appl. Phys. Lett., 103(2), p. 024102.

[12] Li, C., and Peterson, G. P., 2008, "Experimental Studies on CHF of Pool Boiling on Horizontal Conductive Micro Porous Coated Surfaces," AIP Conference Proceedings 969(12), Albuquerque, NM, Feb. 10-14, pp. 12-20.

[13] Chi, W., Sampath, S., and Wang, H., 2006, "Ambient and High-Temperature Thermal Conductivity of Thermal Sprayed Coatings," J. Therm. Spray Technol., 15(14), pp. 773-778.

[14] Dixon, A. G., 1988, "Wall and Particle-Shape Effects on Heat Transfer in Packed Beds," Chem. Eng. Commun., 71(1), pp. 217-237.

[15] Deng, D., Tang, Y., Shao, H., Zeng, J., Zhou, W., and Liang, D., 2014, "Effects of Structural Parameters on Flow Boiling Performance of Reentrant Porous Microchannels," J. Miromech. Microeng., 24(6), p. 065025.

[16] Lin, Y. J., and Hwang, K. S., 2009, "Effects of Powder Shape and Processing Parameters on Heat Dissipation of Heat Pipes With Sintered Porous Wicks," Mater. Trans., 50(10), pp. 2427-2434. 
[17] Bear, J., 1988, Dynamics of Fluids in Porous Media, Dover Publications, New York.

[18] Vafai, K., ed., 2015, Handbook of Porous Media, 3rd, ed., CRC Press, Taylor \& Francis Group, Boca Raton, FL.

[19] Ranjan, R., Murthy, J. Y., Garimella, S. V., and Vadakkan, U., 2011, "A Numerical Model for Transport in Flat Heat Pipes Considering Wick Microstructure Effects," Int. J. Heat Mass Transfer, 54(1-3), pp. 153-168.

[20] Bodla, K. K., Weibel, J. A., and Garimella, S. V., 2013, "Advances in Fluid and Thermal Transport Property Analysis and Design of Sintered Porous Wick Microstructures," ASME J. Heat Transfer, 135(6), p. 061202.

[21] Aziz, A. A., Saury, C., Xuan, V. B., and Young, P., 2005, "On the Material Characterization of a Composite Using Micro CT Image Based Finite Element Modeling," Proc. SPIE 6176, Nondestructive Evaluation and Health Monitoring of Aerospace Materials, Composites, and Civil Infrastructure V, p. 617605.

[22] Watson, I. G., Lee, P. D., Dashwood, R. J., and Young, P., 2006, "Simulation of the Mechanical Properties of an Aluminum Matrix Composite Using X-Ray Microtomography," Metall. Mater. Trans. A, 37(3), pp. 551-558.

[23] Tabor, G., Young, P. G., West, T. B., and Benattayallah, A., 2007, "Mesh Construction From Medical Imaging for Multiphysics Simulation: Heat Transfer and Fluid Flow in Complex Geometries," Eng. Appl. Comput. Fluid Mech., 1(2), pp. 126-135.

[24] Bodla, K. K., Murthy, J. Y., and Garimella, S. V., 2010, "MicrotomographyBased Simulation of Transport Through Open-Cell Metal Foams," Numer. Heat Transfer Part A, 58(7), pp. 527-544.

[25] Bodla, K. K., Murthy, J. Y., and Garimella, S. V., 2012, "Direct Simulation of Thermal Transport Through Sintered Wick Microstructures," ASME J. Heat Transfer, 134(1), p. 012602.

[26] Lienhard, J. H., and Dhir, V. K., 1973, "Hydrodynamic Prediction of Peak Pool-Boiling Heat Fluxes From Finite Bodies," ASME J. Heat Transfer, 95(2), pp. $152-158$.

[27] Davis, J. R., 2001, Copper and Copper Alloys (ASM Specialty Handbook), ASM International, Materials Park, OH, pp. 222-241.

[28] Upadhyaya, G. S., 2002, Powder Metallurgy Technology, Cambridge International Science Publishing, Cambridge, UK, pp. 18-21.
[29] Zhao, Y. Y., Fung, T., Zhang, L. P., and Zhang, F. L., 2005, "Lost Carbonate Sintering Process for Manufacturing Metal Foams," Scr. Mater., 52(4), pp. 295-298.

[30] Webb, R. L., 1981, "Nucleate Boiling on Porous Coated Surfaces," Heat Transfer Eng., 4(3-4), pp. 71-82.

[31] 3M Corporation, 2000, "Fluorinert Electronic Liquid FC-72 Product Information 98-0212-2308-0 (HB)," 3M Corporation, St. Paul, MN.

[32] Simpleware, 2009, "ScanIP, ScanFE, and ScanCAD Tutorial Guide for SIMPLEWARE 7.0," Simpleware Ltd., Exeter, UK.

[33] MathWorks, 2014, "MATLab 8.3," The MathWorks Inc., Natick, MA.

[34] Devore, J. L., 2009, Probability and Statistics for Engineering and the SciencesBrooks/Cole Cengage Learning, Brooks/Cole Cengage Learning, Belmont, CA.

[35] Esbensen, K. H., Guyot, D., Westad, F., and Lars, P., 2002, Multivariate Data Analysis - in Practice: An Introduction to Multivariate Data Analysis and Experimental Design, CAMO, Oslo, Norway.

[36] McHale, J. P., Garimella, S. V., Fisher, T. S., and Powell, G. A., 2011, "Pool Boiling Performance Comparison of Smooth and Sintered Copper Surfaces With and Without Carbon Nanotubes," Nanoscale Microscale Thermophys. Eng., 15(3), pp. 133-150.

[37] Polezhaev, Y. V., and Kovalev, S. A., 1990, "Modeling Heat Transfer With Boiling on Porous Structures," Therm. Eng., 37(12), pp. 617-620.

[38] Childs, E. C., and Collis-George, N., 1950, "The Permeability of Porous Materials," Proc. R. Soc. A: Math. Phys. Eng. Sci., 201(1066), pp. 392-405.

[39] Millington, R. J., and Quirk, J. P., 1961, "Permeability of Porous Solids," Trans. Faraday Soc., 57, pp. 1200-1207.

[40] Marshall, T. J., 1958, "A Relation Between Permeability and Size Distribution of Pores," J. Soil Sci., 9(1), pp. 1-8.

[41] Hashin, Z., and Shtrikman, S., 1962, "A Variational Approach to the Theory of the Effective Magnetic Permeability of Multiphase Materials," J. Appl. Phys., $33(10)$, p. 3125.

[42] Landauer, R., 1952, "The Electrical Resistance of Binary Metallic Mixtures,” J. Appl. Phys., 23(7), p. 779.

[43] Kirkpatrick, S., 1973, "Percolation and Conduction," Rev. Mod. Phys., 45(4), pp. 574-588. 